\title{
Las investigaciones históricas sobre el Vaticano II. Estado de la cuestión y perspectivas de trabajo
}

\author{
Carlos Schickendantz \\ CENTRO TEOLÓGICO MANUEL LARRAÍN \\ UNIVERSIDAD ALBERTO HURTADO \\ carlosschickendantz@gmail.com
}

Las publicaciones científicas sobre el Concilio han adquirido un número tal que dificulta su seguimiento y ponderación. Además, a un temario muy variado, le acompaña también una gran diversidad en la calidad de lo que se publica. Por tanto, el discernimiento de lo que es de mayor valor resulta, a la vez, necesario y complejo. Paralelamente, otra impresión se hace evidente para el lector, impresión que puede visibilizarse con el título de una nota en el periódico italiano La Repubblica, del 2 de julio de 2005, al informar la presentación de un libro editado por la Libreria Editrice Vaticana, de A. Marchetto, al cual me refiero más abajo: "È guerra sul Concilio" ${ }^{1}$. Efectivamente, quien sigue con interés el diálogo y la bibliografía internacional en torno al Vaticano II se ha acostumbrado ya al lenguaje bélico de los distintos autores. Se trata de un campo de batalla con, al menos, dos focos bien definidos y estrechamente vinculados: lo histórico y lo hermenéutico.

Joachim Schmiedl ha distinguido recientemente tres etapas cronológicas sucesivas en la investigación científica sobre el Concilio. La primera, que incluyó las traducciones a las distintas lenguas de los documentos finales y, particularmente, los primeros comentarios; el más significativo de ellos fue el contenido en los tres volúmenes del Lexikon für Theologie und Kirche, publicado entre 1966 y 1968 por los principales teólogos conciliares (Congar, Rahner, Ratzinger, Grillmeier, Philips, Semmelroth, etc.). La segunda fase la ubica Schmiedl en torno al Sínodo extraordinario de 1985 centrada en la idea de una eclesiología de comunión. La

1 http://ricerca.repubblica.it/repubblica/archivio/repubblica/2005/07/02/guerrasul-concilio.html?ref=search 
tercera fase, más amplia y dinámica, la advierte el teólogo de Vallendar, Alemania, a partir de 1990 con el trabajo del equipo internacional dirigido por Giuseppe Alberigo, la llamada escuela de Bolonia ${ }^{2}$. Atendiendo a esta esquematización, entre otras posibles, la presente contribución presta atención particularmente a esta tercera fase, la de la "aceleración del debate" en palabras de G. Ruggieri, cuya característica distintiva, anota el teólogo italiano, "è il carattere 'caldo"”3.

Precisamente, una de las razones por las cuales existe una estrecha relación entre los trabajos históricos y los hermenéuticos se debe a la polémica, al "caluroso" debate, que surgió a partir de la publicación de la obra en cinco volúmenes y traducida a siete idiomas dirigida por Giuseppe Alberigo,junto a un amplio comité internacional: Historia del Concilio Vaticano $I I^{4}$. Si bien la edición italiana se publicó recién entre los años 1995 y 2001, los trabajos habían comenzado luego del Sínodo extraordinario de 1985. Las críticas a esta obra condujeron a una "politización del debate": se produjo un desplazamiento creciente, desde lo histórico hacia el terreno de lo hermenéutico, en el cual la interpretación se utilizó, cada vez más, "como arma" al servicio de un "interés político" que, en buena medida, constituyó el "factor más importante" que pri-

2 Cf. J. Schmied,, "Visionärer Anfang oder Betriebsunfall der Geschichte? Tendenzen der Forschung zum Zweiten Vatikanischen Konzil”, Theologische Revue 108 (2012) 4-18, 4-6. Existen múltiples intentos de distinguir etapas en el posconcilio. La de Schmiedl que cito se centra en los trabajos de investigación. Dos de los intentos más importantes en una periodización más general pueden considerarse: H. J. PotTMeYer, "Hacia una nueva fase de recepción de Vaticano II. Veinte años de hermenéutica del Concilio", en G. Alberigo - J.-P. Jossua (eds.), La recepción de Vaticano II (Cristiandad, Madrid 1987), 49-67; M. FagGioli, Vatican II. The Battle for Meaning (Paulist Press, New Jersey 2012), 1-18.

3 "Ricezione e interpretazioni del Vaticano II. Le ragioni di un dibattito", en A. Melloni - G. Ruggieri (eds.), Chi ha paura del Vaticano II? (Carocci editore, Roma 2009), 17-44, 17, 19.

4 G. Alberigo(dir.), Historia del Concilio Vaticano II. Volumen 1. El catolicismo hacia una nueva era. El anuncio y la preparación (enero 1959-setiembre 1962), (Síguemel Peeters, Salamanca 1999); Volumen II. La formación de la conciencia conciliar. El primer período y la primera intersesión (octubre 1962-setiembre 1963),(Síguemel Peeters, Salamanca 2002); Volumen III. El concilio adulto. El segundo período y la segunda intersesión (setiembre 1963-setiembre 1964), (Sígueme/Peeters, Salamanca 2006); Volumen IV. La Iglesia como comunión. El tercer periodo y la tercera intersesión (setiembre 1964-setiembre 1965), (Sígueme/Peeters, Salamanca 2007); Volumen V. Un concilio de transición. El cuarto periodo y la conclusión del concilio (setiembrediciembre 1965), (Sígueme/Peeters, Salamanca 2008). 
vilegia una u otra interpretación en estos años ${ }^{5}$. El famoso discurso de diciembre de 2005 de Benedicto XVI formó parte activa de este debate $\mathrm{y}$, con un grado importante de simplificación, fue repetido una y otra vez alimentando la politización. Para caracterizar el clima creado varios autores no dudaron en utilizar expresiones bélicas: un "campo de batalla" (Routhier), la "batalla por el significado" (Faggioli) y, refiriendo a la situación posconciliar más general, incluso Benedicto recurrió a este tipo de imágenes: citó en 2005 una expresión de San Basilio, "una batalla naval en la oscuridad de la tempestad", con una "descripción dramática" que, a su juicio, "refleja algo de lo que ha acontecido" en el posconcilio 6 .

Esa inflación y politización hermenéutica explica una reacción reciente de varios historiadores/as. Silvia Scatena, investigadora en Módena y Bolonia, por ejemplo, llama la atención sobre un cierto desequilibrio entre una hipertrófica literatura hermenéutica con fundamentos históricos frágiles, que dice más de la actual situación de la Iglesia que del Concilio mismo y una investigación propiamente histórica, que continúa en la producción de nuevos conocimientos. Se trata de "un debate a menudo asfixiado por el recurso a polaridades abstractas o antagonismos ficticios"', como el de la continuidad-discontinuidad, la dialéctica entre evento y corpus doctrinal, o la de letra y espíritu. En términos idénticos se expresa Étienne Fouilloux, de la Université Lumière Lyon 2, o, muy semejantes, John O’Malley, jesuita de la Georgetown University, Washington. Este último distingue en la situación actual "tres esferas casi herméticamente selladas de interpretación del concilio: histórica, teológica e institucional. Una situación triste”. A su juicio, las dos primeras interactúan un poco, la tercera se ha aislado a sí misma, advierte ${ }^{8}$. Queda por ver en qué medida la nueva situación internacional de la Iglesia, con el cambio de papado, favorece un espacio menos polémico.

5 Cf. G. Routhier, "L'herméneutique de Vatican II. Réflexions sur la face cachée d'un débat", Recherches de Science Religieuse 100 (2012) 45-63, 46, 51.

6 Cf. M. Faggioli, Vatican II. The Battle for Meaning, Benedicto XVI, "Discurso a la Curia romana”, 22/12/2005, www.vatican.va/holy_father/benedict_xvi/speeches/

7 Cf. "1962-2012: la storia dopo la Storia? Contributi e prospettive degli studi sul Vaticano II dieci anni dopo la Storia del concilio", Cristianesimo nella storia 34 (2013) $1-13,5$.

8 Cf. las expresiones de É. Fouilloux y J. O’Malley en "Round Table - Vatican II, 1962-2012. The history after the History?", Cristianesimo nella storia 34 (2013) 423-460, 444, 427 respectivamente. 
A partir de mis lecturas pienso que una presentación ordenada del estado de la investigación sobre el Vaticano II podría distinguir tres áreas. En primer lugar, una histórica, que atiende al evento mismo, su preparación próxima y remota y su desarrollo. Segunda, los estudios sistemáticos, en los cuales se destaca particularmente la perspectiva hermenéutica. Tercera, panoramas o investigaciones puntuales que refieren a los diversos y múltiples procesos de recepción, principalmente por el criterio regional. No es posible trazar una línea clara de división en muchos autores y trabajos que pertenecen a más de una de las áreas referidas. Pienso, no obstante, que es útil su distinción.

En las páginas que siguen desarrollo este propósito: presentar los textos y autores/as más relevantes y, particularmente, discernir las líneas de trabajo y argumentos principales que están ocupando a la comunidad teológica internacional; en varios lugares destaco los aportes latinoamericanos. Pero dada la cantidad de material, establezco una delimitación importante: analizo aquí solamente los trabajos históricos. En próximas contribuciones afrontaré los otros dos momentos aludidos: los estudios sistemático-hermenéuticos y los referidos a los procesos de recepción.

De modo particular, el presente artículo da cuenta, siquiera someramente, de tres encuentros académicos desde la perspectiva histórica: el primero, realizado en la Université Laval, Québec, en octubre de 2010, sobre los movimientos de reforma en el siglo XX y su recepción en el Vaticano II; el segundo, celebrado en febrero de 2010 en Munich, con investigadores exclusivamente de lengua alemana (Alemania, Austria y Suiza) y, finalmente, uno organizado en Módena, Italia, en febrero de 2012, para conmemorar los diez años de la publicación de la obra internacional en cinco volúmenes dirigida por G. Alberigo y explicitar las nuevas prospectivas de trabajo, "the history after the History", como lo llaman los editores de la publicación. Constato, además, que existen tres trabajos muy destacados que ofrecen una información bibliográfica comentada de lo mucho que se publica: me refiero a los realizados por Massimo Faggioli (University of St. Thomas - St. Paul, MN, USA) ${ }^{9}$,

\footnotetext{
M. Faggioli, "Concilio Vaticano II: bolletino bibliografico (2000-2002)", Cristianesimo nella storia 24 (2003) 335-360; "Concilio Vaticano II: bolletino bibliografico (2002-2005)”, Cristianesimo nella storia 26 (2005) 743-767; "Council Vatican II: Bibliographical overview 2005-2007”, Cristianesimo nella storia 29 (2008) 567-610; "Council Vatican II: Bibliographical overview 2007-2010", Cristianesimo nella storia 32 (2011) 755-791.
} 
Jared Wicks (Pontifical College Josephinum, Columbus, OH, USA) ${ }^{10}$ y Gilles Routhier (Université Laval, Québec, Canadá) ${ }^{11}$; actualizados periódicamente, son probablemente los de mejor calidad y amplitud.

\section{El debate por la "verdadera historia” - ¿Roma contra Bolonia?}

a) Aun sus críticos deben reconocer que la obra del equipo internacional dirigido por Alberigo ha representado un salto cualitativo en los estudios sobre el suceso conciliar. Representa un punto de referencia obligada en la historiografía del Vaticano II, ha entrado a formar parte del proceso mismo de recepción y ha inaugurado una nueva fase de estudio e investigaciones ${ }^{12}$. En opinión de Mathijs Lamberigts, de la Katholieke Universiteit Leuven, Bélgica, donde funciona unos de los centros de investigación más destacados sobre el Vaticano II $^{13}$, las líneas maestras de la Historia de Alberigo se verifican, años después, como correctas. Incluso, añade, los nuevos datos que surgen de los archivos a partir de 2005, por importantes y útiles que resultan, no añaden "conocimientos nuevos espectaculares" a dicha obra ${ }^{14}$. Por otra parte, como reconoce Alberto

10 J. WiCKs, "New Light on Vatican Council II", The Catholic Historical Review 92 (2006) 609-628; "More Light on Vatican Council II", The Catholic Historical Review 94 (2008) 75-101; "Further Light on Vatican Council II", The Catholic Historical Review 95 (2009) 546-569; "Still More Light on Vatican Council II", The Catholic Historical Review 98 (2012) 476-502.

11 G. Routhier, "Recherches et publications récents autour de Vatican II", Laval théologique et philosophique 53 (1997) 435-454 y ha continuado en la misma revista: 55 (1999) 115-149; 56 (2000) 543-585; 58 (2002) 177-203; 59 (2003) 583-606; 60 (2004) 561-577; 61 (2005) 561-577; G. Routhier - M. Quisinsky, "Recherches et publications récents autour de Vatican II", Laval théologique et philosophique 64 (2008) 783-824. Para el ámbito exclusivamente alemán, es útil el panorama de F.-X. Bischof, "On the State of German-speaking Research on Vatican II", Cristianesimo nella storia 34 (2013) 57-68.

12 Cf. S. Scatena, "1962-2012: la storia dopo la Storia?”, 2s. Por ejemplo, no es sospechoso de simpatía el juicio de Roberto de Mattei que con su trabajo se ubica en las antípodas del de Alberigo. Afirma que la Historia en cinco volúmenes "constituye una obra de referencia, aunque discutida y discutible, de la cual no se puede prescindir", Il Concilio Vaticano II. Una storia mai scritta (Lindau, Torino 2010), 8. Más aún, piensa que "no existe ninguna alternativa seria a la escuela de Bolonia”, Il Concilio ... 21.

13 "Centre for the Study of the Second Vatican Council", http://theo.kuleuven.be/en/ research/centres/centr_vatii/

14 Cf. las expresiones de M. Lamberigts en "Round Table - Vatican II, 1962-2012", 437-441. 
Melloni, la nueva generación de estudiosos, bien visibles en el congreso de Módena citado, constituye claramente "el fruto de aquella gran obra, que les permite no partir de cero, sino de un punto avanzado"15.

Dicha Historia se inició propiamente en diciembre de 1988 con una primera reunión en una conferencia internacional celebrada en el Centre Sèvres, París. En 1995 se publicó el primer volumen en italiano, el quinto y último en 2001 (en español: 1999-2008). La obra completa, traducida a siete idiomas, incluye 36 capítulos y fue acompañada, además, por una docena de publicaciones científicas y ocho reuniones internacionales celebrados por los especialistas del proyecto (teólogos e historiadores de Europa, Norteamérica y Latinoamérica). Desde el inicio fue claro que no se pretendía elaborar una nueva serie de comentarios, sino una reconstrucción del acontecimiento lo más precisa posible a partir de las múltiples fuentes existentes en ese momento ${ }^{16}$. A. Melloni, en un nuevo prólogo, de 2012, a la reedición italiana de la obra, recuerda que la pregunta que dirigió el trabajo, formulada ya al inicio, no era “ ¿cómo se ha llegado a la aprobación del corpus de las decisiones del Vaticano II?, sino, ¿cómo se ha desarrollado efectivamenteel Vaticano II y cuál ha sido su significado?”17.

Como explicita el mismo Alberigo el trabajo está realizado mediante el desarrollo del método histórico-crítico; esto no implica negar la "dimensión meta-racional: la inspiración del Espíritu" conforme a la autocomprensión teológica ${ }^{18}$. En ese marco, destaca repetidamente, "se ha preferido desentrañar el curso efectivo de las experiencias de la asamblea, siguiendo incluso sus innegables tortuosidades, en vez de ofrecer una reconstrucción temática, seguramente más rectilínea pero también menos

15 Cf. las expresiones de A. Mellonien "Round Table - Vatican II, 1962-2012", 453460, 455.

16 Cf. al respecto el apéndice en el último volumen: G. Alberigo, "Las fuentes sobre el concilio Vaticano II", en id., Historia del Concilio Vaticano II. Volumen V, 571-577.

17 "Il Vaticano II e la sua storia. Introduzione alla nueva edizione, 2012-2014", en G. Alberigo (dir.), Storia del concilio Vaticano II. Volume I, (Il Mulino, Bologna 2012, Nuova edizione), IX- LVI, XIX. Esta introducción de Melloni, a quien corresponde como sucesor de G. Alberigo muerto en 2007 la dirección científica de la "Fondazione per le scienze religiose" de Bologna, Italia (http://www.fscire. it/), es extremadamente útil para comprender la "historia de la historia del Vaticano II". Prácticamente un resumen de dicha introducción es su publicación posterior: "Vatican II and the History of Vatican II", Pacifica 26 (2013) 134-154.

18 Cf. G. Alberigo, Historia del Concilio Vaticano II. Volumen II, 12. 
respetuosa con la realidad concreta del acontecimiento" ${ }^{19}$. Ni una presentación "de crónica", aclara en otro lugar, "ni tampoco a partir del esquema interpretativo de los dieciséis documentos conclusivos, como parecía obvio en los años ochenta" ${ }^{20}$. Paralelamente, se explicita que los criterios hermenéuticos "que presidían la empresa" fueron discutidos al inicio de los trabajos y ellos "han controlado eficazmente todas las investigaciones" 21. El punto de vista está plenamente reconocido. No se ignora la existencia de una perspectiva hermenéutica clara, focalizada particularmente en estos argumentos: el carácter de acontecimiento del Concilio, no una mera suma de decisiones y documentos finales, la intención de Juan XXIII, el carácter "pastoral", el aggiornamento como objetivo, la importancia hermenéutica de la praxis del "compromiso" y de la búsqueda de la unanimidad en el Concilio ${ }^{22}$. Hay un círculo de alimentación recíproca entre el método histórico-crítico y la perspectiva con que se mira. La reciente afirmación de M. Faggioli creo que refleja lo sucedido: "la corriente principal de la teología e historiografía católica aceptó largamente los criterios hermenéuticos del Vaticano II propuestos por Giuseppe Alberigo"; gracias a ese trabajo histórico "muy pocos" cuestionan la necesidad de usar la categoría de evento para la comprensión del significado del Vaticano $\mathrm{II}^{23}$. Efectivamente, la idea de acontecimiento o evento, que no está exenta de posibles malentendidos, resulta un concepto clave: ofrece una mirada más rica y diferenciada sobre la complejidad del proceso conciliar de búsqueda y formulación de la verdad ${ }^{24}$.

19 Cf. G. Alberigo, Historia del Concilio... Volumen III, 9.

20 G. Alberigo, "El Vaticano II y su historia”, Concilium 312 (2005) 13-25, 20.

21 Cf. G. Alberigo, Historia del Concilio Vaticano II. Volumen V, 12.

22 Cf. G. Alberigo, "Criterios hermenéuticos para una historia del Vaticano II", en J. O. Beozzo(ed.), Cristianismo e iglesias de América Latina en vísperas del Vaticano II (Editorial DEI, San José, Costa Rica 1992), 19-31. Ahora en la colección de ensayos: "Criteri ermeneutici per una storia del Vaticano II", en G. Alberigo, Transizione epocale. Studi sul concilio Vaticano II (II Mulino, Bologna 2009), 29-45.

23 “Council Vatican II: Bibliographical overview 2007-2010", 758, 768.

24 GÜNTher Wassilowsky, profesor de historia de la Iglesia en la KatolischTheologische Universität Linz, Austria, y coeditor de la versión alemana de los dos últimos volúmenes de la Historia dirigida por Alberigo a la muerte de K. Wittstadt, ha planteado en 2012, con un nuevo acento, la importancia de este concepto para la comprensión teológica de un concilio. Cf. "Kontinuum - Reform - (Symbol-) Ereignis? Konzilsgeschichtsschreibung nach Alberigo", en F.-X Bischof (ed.), Das II. Vatikanische Konzil (1962-1965). Stand und Perspektiven kirchenhistorischer Forschung im deutschsprachigen Raum (Kohlhammer, Stuttgart 2012), 27-44, 40. 
b) ¿Cuáles son las principales objeciones que ha recibido la obra de Alberigo? Para abordar con orden esta cuestión refiero a otro trabajo histórico que ha tenido repercusión por varias razones: Il Concilio Ecuménico Vaticano II. Contrappunto per la sua storia, de Agostino Marchetto, anterior nuncio y secretario del Pontificio Consejo para la Pastoral de Migrantes entre 2001 y 2010. Su trabajo, presentado en junio de 2005 por el entonces presidente de la conferencia episcopal italiana, el cardenal C. Ruini y editado por la Editrice Vaticana, constituiría, un ejemplo de una necesaria reconstrucción del Vaticano II y su "verdadera historia”, el contrapunto -según su subtítulo- a la escuela de Bolonia y el fin de la "hegemonía" sobre la interpretación del Vaticano II. Así se expresa en su prefacio: "Mi propósito es contribuir a conseguir finalmente una historia del Vaticano II que venza los graves condicionamientos -se comprende así la introducción del término 'contrapunto' en el subtítulo del libro- planteados hasta ahora, a este respecto, por una visión que he definido como ideológica desde el comienzo y que se impone, de una manera monopolística, en el mercado editorial" 25 . El texto, que ya ha sido traducido al español (2008), al ruso (2009) y al inglés (2010), recoge 52 ensayos, solo 6 inéditos, publicados entre los años 1989 y 2003; 33 de ellos aparecieron en Apollinaris, una revista de la Pontificia Università Lateranense, 14 de ellos en L'Osservatore Romano, el diario oficial del Vaticano. Los artículos tienen la forma de recensiones con breves comentarios intercalados. Posteriormente él mismo ha calificado esta obra suya como "la primera historia de la historiografía relativa al Concilio", desde 1990 al $2005^{26}$. Creo que, desde este punto de vista, "historia de la historiografía", no puede negarse que el trabajo presta un servicio a los lectores. En 2012 el autor ha publicado un nuevo libro de naturaleza semejante al anterior, Il Concilio Ecuménico Vaticano II. Per la sua corretta ermenutica; posee 35 capítulos, la mitad de ellos inéditos, los restantes publicados en las mismas fuentes antes citadas.

25 A. Marchetto, Il Concilio Ecuménico Vaticano II. Contrappunto per la sua storia (Librería Editrice Vaticana, Città del Vaticano 2005). Cito la traducción española e introduzco correcciones con libertad: El Concilio Ecuménico Vaticano II. Contrapunto para su historia (Edicep, Valencia 2008), 11.

26 A. Marchetto, Il Concilio Ecuménico Vaticano II. Per la sua corretta ermenutica, (Librería Editrice Vaticana, Città del Vaticano 2012), 24. Marchetto afirma esto al comentar otro estudio historiográfico, fruto de una tesis doctoral: F. S. VENUTO, La recezione del Concilio Vaticano II nel dibattito storiografico dal 1965 al 1985. Riforma o discontinuità? (Effata Editrice, Torino 2011). 
Cometido central de este emprendimiento editorial es la crítica a la Historia de Alberigo. Ante todo, ha sido cuestionado el punto central de su perspectiva: el Vaticano II como evento; opacaría la centralidad de los textos oficiales definitivos en beneficio de un espíritu conciliar más o menos independiente de la letra ${ }^{27}$. Por otra parte, se ha advertido el exceso de aprecio por la figura de Juan XXIII y, por contraste, una mirada más negativa sobre el rol de Pablo VI en la conducción de la asamblea ${ }^{28}$. En tercer lugar, se le reprocha a Alberigo un acento excesivo al subrayar la novedad, el carácter de transición a una nueva época, de giro en la historia de la Iglesia ${ }^{29}$. En cuarto término, se le critica el uso frecuente de otras fuentes, particularmente de los diarios y fondos archivísticos privados; este procedimiento iría en perjuicio del tratamiento de

27 Cf. El Concilio Ecuménico Vaticano II. Contrapunto para su historia, 126: “...la famosa infravaloración, característica del 'grupo boloñés', de los textos conciliares, como si se tratara de algo 'un poco demasiado abstracto'”. Cf. El Concilio Ecuménico $\ldots 145,177,253,278,310,340$. Uno de sus calificativos más frecuentes para con los diversos autores de la obra y otros teólogos afines (H. Pottmeyer, K. Schatz, O. H. Pesch, etc.): "ideológico", cf. El Concilio Ecuménico ... 11, 171, 173, 188, 232, 257, 278, 337, 370, 389, 403, 406, 414, 416, etc. La ceguera sobre los propios presupuestos, una suerte de ingenuidad hermenéutica, es llamativa. Por ejemplo, El Concilio Ecuménico ... 390: "cuando se está libre de prejuicios...”. Habla allí de sí mismo. Igualmente ibid., 404: "Cuando se está libre de prejuicios...”. Cf. también A. Marchetto, Il Concilio Ecuménico Vaticano II. Per la sua corretta ermenutica, 320. Este tipo de repeticiones se debe también a una característica fundamental del libro: en lo sustancial es una suma de recensiones anteriormente publicadas. Es llamativa la manera cómo en el libro se repiten textualmente párrafos completos, más de cuatro veces algunos, incluso páginas enteras.

28 El Concilio Ecuménico Vaticano II. Contrapunto para su historia, 153, 155, 223-224. Un ejemplo indicativo: luego de criticar al cardenal Agostino Bea por su expresión acerca de Juan XXIII como "el papa del Concilio", por opacar a Pablo VI, acoge con agrado la expresión de J. Ratzinger sobre Pablo VI como "el verdadero papa del Concilio", ibid., 334, 337. De un extremo al otro.

29 Wassilowsky constata que no existe ningún lugar en el libro de Marchetto donde pueda encontrarse un ejemplo en el sentido que el Vaticano II ha emprendido un nuevo camino o ha puesto un nuevo acento. Su dirección argumentativa tiene una línea definida: el Vaticano II es interpretado ante todo a la luz de Trento y del Vaticano I. Cf. "Kontinuum - Reform - (Symbol-) Ereignis?”, 28. Porque ya la crítica de Marchetto en 2005 estaba fuertemente focalizada en la idea de continuidadruptura es explicable que el discurso de Benedicto del mes de diciembre de 2005 deviniera un texto fundamental, como puede corroborarse en su libro de 2012, y que, además, disputara sobre su interpretación. Cf. Il Concilio Ecuménico Vaticano II. Per la sua corretta ermenutica, 219, 223. 
las Actas oficiales ${ }^{30}$. Evaluar cada una de estas observaciones excede las posibilidades de esta contribución. No puede negarse que el trabajo de Alberigo tiene determinados acentos, por ejemplo su inocultable simpatía con Juan XXIII, pero existe una opinión mayoritaria y fundada de historiadores y teólogos, un consensus theologorum, si bien no unánime, sobre la seriedad de este emprendimiento historiográfico, más allá de las limitaciones que puedan encontrarse en él ${ }^{31}$.

No es posible entrar aquí en detalles sobre la obra de Marchetto, sin embargo, destaco un par de ideas, más allá de su lenguaje "bélico". El pecado original de Alberigo, a ojos de Marchetto, indudablemente es la utilización de la categoría de acontecimiento. Creo, no obstante, que identificar la categoría de evento con la idea de que ella implica "desconectar el acontecimiento y las decisiones conciliares" no representa el pensamiento de la obra, ni de sus autores, más allá de que una u otra expresión sean más o menos felices. Por otra parte, identificar la idea de acontecimiento con la de "ruptura" con la tradición, también parece un exceso ${ }^{32}$. En el libro de 2012 esta crítica se hace más visible aún porque comenta trabajos, además del de Alberigo, de Routhier, Pesch, O'Malley, Theobald, Boeve, Schelkens, Ruggieri, etc. ubicándolos a todos en un capítulo titulado: "Hermenéutica de la ruptura". Se trata de un explícito intento de situar a todos estos autores bajo la crítica del Papa en su discurso de 2005.

30 Cf. A. Marchetto, El Concilio Ecuménico Vaticano II. Contrapunto para su historia, 108, 109, 145, 147, 168, 324, 328, 389, 401, 403, 407, 413. Critica, por ejemplo, la manera frecuente como se cita a Congar, ibid., 154: "Parece haberse convertido en la medida verdadera y justa del pensamiento de toda la Iglesia con sus juicios sobre hombres y cosas" y recomienda verificar esto consultando el índice onomástico. Me parece interesante la observación que se encuentra en las "memorias" de Siri y que Marchetto recoge con agrado: "La historia de este concilio es, en una parte notable, la historia de los peritos, porque se ha revelado una gran anemia de conocimiento teológico tanto en el episcopado como en el Sacro Colegio", citado en ibid., 323.

31 G. RugGieri ofrece un listado de la innumerable cantidad de recensiones que ha recibido la obra. Cf. "Ricezione e interpretazioni del Vaticano II", 42 nota 7.

32 Ilustrativa de esta posición pueden ser los párrafos de páginas 177 y 178, cf. El Concilio Ecuménico Vaticano II. Contrapunto para su historia. Pero abundan los ejemplos, ibid., 242-243, 255, 265, 278, 310, 367, 369, 390, 403, 406, 414. En el libro de 2012 se encuentra la idea con la misma frecuencia, Il Concilio Ecuménico Vaticano II. Per la sua corretta ermenutica, 154, 166, 173, 182, 192, etc. 
Lo cierto es que la obra está muy lejos de la pretensión de una "verdadera historia" 33 . Por ejemplo, resulta llamativo que, de manera frecuente, incluso cuando formula frases que descalifican otras posiciones, no consigne ninguna cita o fuente. Me temo que el severo juicio de G. Routhier no está descaminado: el trabajo de Marchetto, además de su tono polémico, contiene más bien una crítica al trabajo del equipo de Alberigo, que la propuesta de una verdadera contribución, original y positiva. "El autor está más preocupado en demoler el trabajo de otros (sin haberlos comprendido bien siempre), que de arriesgarse él mismo a un trabajo de historia del Concilio" 34 . Efectivamente, "no es una historia alternativa del Concilio", al decir de J. Wicks ${ }^{35}$. Probablemente el que este tipo de posición no pueda competir desde el punto de vista científico y argumentativo ha colaborado a un desplazamiento: de la calidad de las investigaciones hacia la "politización del debate". El discurso de diciembre de 2005 de Benedicto XVI fue utilizado como una aprobación de esta estrategia. La hermenéutica de la ruptura, de la que habla el Papa, fue aplicada por Marchetto a la obra de Alberigo. ¿Interpretaba así correctamente a Benedicto XVI o iba más allá que él? Por otra parte, puede quedar abierta la cuestión de si esta "polémica italiana" (G. Routhier), o de lucha de "escuelas", "Roma contra Bolonia”, como afirma K. Schelkens ${ }^{36}$, representa exactamente lo que Faggioli sugiere: una reproducción, cincuenta años después, de los "mismos argumentos" existentes en el Concilio entre una minoría atrincherada en

33 Cf. A. Marchetto, El Concilio Ecuménico Vaticano II. Contrapunto para su historia, 178: "Vamos a terminar manifestando nuestro aprecio por los talentos que los autores manifiestan en la obra, pero que son dignos de mejor causa, la de la verdad histórica sobre el Vaticano II".

34 G. Routhier, "L'herméneutique de Vatican II", 51 nota 21.

35 J. WiCKS, "New Light on Vatican Council II", 613. Contribuciones y limitaciones de la obra de Roberto de Mattei, cf. particularmente J. WiCKS, "Still More Light on Vatican Council II", 498-502; M. FAGGIOLI, "Council Vatican II: Bibliographical overview 2007-2010", 764.

36 "La réception de 'Dei Verbum' entre thélogie et histoire", en G. RouTHIER - G. Jobin (ed), L'Autorité et les Autorités. L'herméneutique théologique de Vatican II, (Cerf, Paris 2010), 51-68, 52. Cf. también la fuerte descalificación del trabajo de Marchetto que hace A. Melloni, "Breve guida ai giudizi sul Vaticano II", en A. Melloni- G. Ruggieri, Chi ha paura del Vaticano II?, 107-145, 130. Una, de las tantas, respuestas de MARCHETTO al escribir el comentario a la obra de R. de Mattei, afirma: "Tenemos ahora pues dos historias hechas por extremistas...", comparándola con la de Alberigo, Il Concilio Ecuménico Vaticano II. Per la sua corretta ermenutica, 242. 
la curia romana, "Curial party", y sectores de la llamada mayoría conciliar o "anti-Curial opposition", en las palabras del historiador italiano ${ }^{37}$. Otra observación de Faggioli, entonces, parece acertada: "es un hecho que la mayoría de las universidades y centros académicos romanos (Rome-based) están ausentes de la parte constructiva del debate historiográfico sobre el Vaticano II"38.

c) En el ámbito de lengua inglesa, el jesuita norteamericano John O’Malley, profesor en Georgetown, Washington, ha publicado en 2008 un trabajo que ya ha sido traducido al italiano (2010), al francés(2011) y al español (2012): What Happened at Vatican II?39 . El autor, especialista en la historia moderna temprana de Europa, ha incursionado con pocos pero buenos trabajos referidos al Vaticano $\mathrm{II}^{40}$. O’Malley sitúa a su texto como "un libro básico acerca del concilio" con la pretensión de brindar una "historia esencial", que ponga de relieve las "cuestiones que emergen" en la narración ubicándolas en sus contextos históricos y teológicos y que, finalmente, ofrezca "algunas claves que permitan percibir

37 “Council Vatican II: Bibliographical overview 2005-2007”, 608. La publicación de Brunero Gherardini, profesor emérito de eclesiología y ecumenismo de la Universidad Lateranense, Roma, y director de la revista Divinitas, que se posiciona explícitamente en favor del libro de Marchetto, desde el punto de vista hermenéutico va aún más allá de este último; no se trata ante todo de un libro histórico.

38 "Council Vatican II: Bibliographical overview 2005-2007”, 509.

39 ¿Qué pasó en el Vaticano II?, (Sal Terrae, Santander 2012); What Happened at Vatican II? (Harvard, Cambridge, MA 2008). Cf. la recensión de O. Rusch en Theological Studies 74 (2013) 483.

40 Los dos artículos más detallados son: "Vatican II: Did Anything Happen?", Theological Studies 67 (2006) 3-33 (desarrolla más detenidamente tres puntos del libro: los concilios y el Concilio, aggiornamento y ressourcement, el género literario); “'The Hermeneutic of Reform'. A Historical Analysis”, Theological Studies 73 (2012) 517-546 (a la luz del debate sobre la continuidad-discontinuidad suscitada por el discurso de Benedicto XVI de 2005, aborda la problemática del cambio y la reforma desarrollando, también con más detalle, ideas del capítulo segundo del libro: el largo siglo XIX). Existen textos más breves que presentan sus principales aportes: "Cómo la Iglesia cambió durante el Concilio", Mensaje 518 (2003) 22-25 (publicado en America, 2003 con el título The Style of Vatican II es una versión sencilla y bien escrita del artículo "Vatican II: Did Anything Happen?”, de 2006); "Ressourcement y reforma en el Vaticano II”, Concilium 346 (2012) 361-371 (en cierta medida una versión breve del "The Hermeneutic of Reform" de 2012). "El Concilio del acercamiento”, Mensaje 612 (2012) 18-23 (añade información más general, la idea de reconciliación, en un tono sencillo). 
qué objetivos se había propuesto alcanzar el concilio" ${ }^{41}$. Estos objetivos se dirigen a responder a la pregunta del título: ¿qué pasó en el Concilio?

El libro posee casi 500 páginas divididas en siete capítulos, a los que se le suman una introducción y una conclusión. Me atrevo a distinguir tres partes en este material. Ante todo, el relato de lo que en el prólogo el autor llamó la "historia esencial" y que ocupa aproximadamente cinco capítulos (del tercero al séptimo). Esta narración es muy próxima al estilo y contenido de la Historia de Alberigo. En segundo lugar, una muy interesante ubicación del evento en el marco de una perspectiva histórica más amplia, que el autor llama "el largo siglo XIX" (el capítulo segundo); iniciado con la Revolución francesa se cierra con el Vaticano II. Esta lectura representa uno de los aportes del texto en comparación con la obra de Alberigo. En tercer lugar, una serie de consideraciones, diseminadas en la introducción, el capítulo primero y la conclusión que hacen de este libro algo más que un texto meramente histórico. El análisis de lo que O’Malley llama las tres "cuestiones subyacentes" (the issues-under-the-issues) que "proporcionan lentes para interpretar el concilio" 42 , a saber: (1) la manera como se afronta el problema del cambio, "un fenómeno igualmente dominante y perturbador" ${ }^{43}$; aquí es muy interesante el análisis de los conceptos de aggiornamento, ressourcement y desarrollo doctrinal; (2) la relación entre centro y periferia, que tiene un punto central de debate en la temática de la colegialidad y, sobre todo, (3) la cuestión del estilo que, a su juicio, es lo que "lo distingue de todos los demás concilios" «4, y que "estuvo integrado por dos elementos esenciales: un género literario y un vocabulario apropiado" ${ }^{45}$. Dicho género "puede identificarse con toda precisión", practicado desde antiguo y en muchas culturas se lo caracterizó con el nombre de "panegírico". Se trata de un género más literario que filosófico,

41 ¿Qué pasó en el Vaticano II?, 15.

422 ¿Qué pasó ... 9.

43 ¿Qué pasó ... 26.

44 ¿Qué pasó ... 409. Esta temática recorre toda la obra. Cf. por ejemplo la referencia a una intervención de Ottaviani en noviembre de 1962, en la presentación del esquema De fontibus y a otros padres conciliares en esa y otras oportunidades, ¿Qué pasó 193-194, 200-202, 221, 360.

45 ¿Qué pasó ... 72. Creo que este análisis, aquí más precisado, está en plena concordancia con lo afirmado por P. Hünermann sobre el "nuevo tipo de magisterio". Cf. C. SChickendantz, Cambio estructural de la Iglesia como tarea y oportunidad (EDUCC, Córdoba 2005), 129ss. No me detengo más en este aspecto dada la perspectiva histórica de esta contribución. 
que en los tratados clásicos de retórica recibe un nombre técnico: género epidíctico. No se propone aclarar los conceptos, sino realzar el aprecio por una persona, un acontecimiento o una institución y animar al oyente a emular un ideal; no impone, invita, persuade, "su objetivo es conseguir el asentimiento interno" ${ }^{46}$. La manifestación de este "patrón epidíctico" se encuentra en el vocabulario. De allí el trabajo que O’Malley realiza para revisar el texto conciliar: palabras de significado horizontal (pueblo de Dios, colegialidad, etc.), palabras de reciprocidad (cooperación, diálogo, etc.), de humildad (iglesia peregrina y servidora, etc.), de interioridad (carisma, gozo y esperanza, tristeza y angustias, etc.), de cambio (desarrollo, progreso, etc.); se trata de una "unidad literaria particular, única entre los concilios" ${ }^{\prime \prime}$.

En síntesis, "el Vaticano II fue un acontecimiento lingüístico" ${ }^{48}$. El género literario expresa y promueve una manera de ser. "La elección de estilo es una elección de identidad propia, de personalidad y, en este caso, del tipo de institución que el concilio deseaba que fuese la Iglesia" ${ }^{49}$. De esta manera se expresa una orientación global coherente y verificable. Ocuparse de estos asuntos, de estas cuestiones subyacentes, permite explicar la dinámica del concilio, la del catolicismo romano en general, algunas de las tensiones del posconcilio en particular. Como bien apunta O'Malley todas ellas "tienen que ver con la identidad" 00.

d) Existe otra obra histórica digna de relieve. Se trata del libro de Roberto de Mattei, Il Concilio Vaticano II. Una storia mai scritta, 2010. Sobre el valor de esta publicación, en particular su trabajo sobre la minoría conciliar, y sobre sus limitaciones coinciden las opiniones de autores diferentes como Melloni, Marchetto y otros. Junto a la obra de B. Gherardini, A. Marchetto, en su libro de 2012, ubica la de Mattei en un capítulo titulado: "Hermenéutica de la ruptura en la tendencia tradicionalista" ${ }^{51}$.Con claridad formula de Mattei su propósito: se trata de una historia "nunca escrita", como dice el subtítulo, no por el material nuevo que se considera, sino por la manera en que se organizan y comprenden los testimonios y los hechos, en última instancia en una

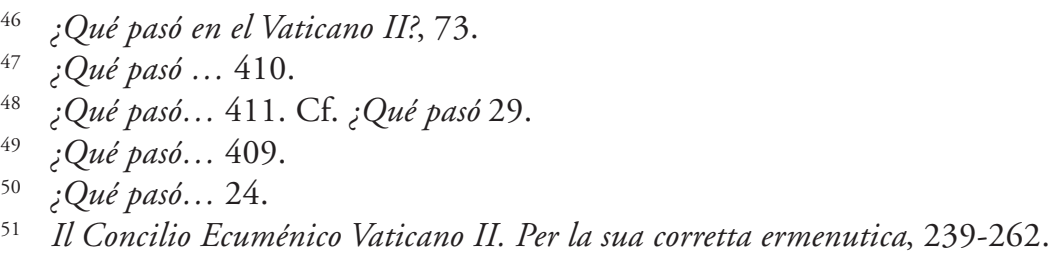


filosofía de la historia o teología de la historia que de Mattei ejemplifica en una obra de Plinio Corrêa de Oliveira, fundador del movimiento conservador "Tradición, Familia y Propiedad"52.

Su perspectiva de lectura es explicitada al inicio de su libro y aflora continuamente, casi en cada página: "un evento es una situación que representa una radical fractura con el pasado" 53 . Por otra parte, el principio marxista de la primacía de la praxis, particularmente en boga en la década del 60, a su juicio, es una clave de lectura para la comprensión de categorías conciliares centrales: aggiornamento, signos de los tiempos, pastoral. Desde allí comprende de Mattei la temática de la praxis histórica como "locus theologicus", en general, la conciencia de la historicidad de la verdad. Por eso su crítica: "la fórmula del aggiornamento por la cual los hombres no tienen que conformarse a las sagradas enseñanzas, sino estas adaptarse a los hombres..." ${ }^{54}$.

A su juicio, el problema no es tanto el posconcilio, sino más bien el Concilio mismo, particularmente a causa de su novedad: su carencia de definiciones dogmáticas que ha abierto a la discusión la naturaleza de estos textos y su aplicación ${ }^{55}$. En una conferencia de 2010 lo expresó con claridad: ninguna supuesta hermenéutica conciliar puede ser causa de la crisis de la Iglesia en el posconcilio, sino el Concilio mismo ${ }^{56}$. Así se entiende, también, la petición que dirige al papa al final del libro para que promueva un "examen profundo del Concilio Vaticano II, en toda su complejidad y extensión, para verificar su continuidad con los veinte Concilios precedentes" 57 .

Aludiendo al rechazo de la mayor parte de los esquemas preparatorios, de Mattei argumenta que "el mayor cambio introducido, más que en el contenido, fue en el lenguaje de los esquemas. Fue adoptado en efecto, recuerda el cardenal Siri, el criterio decisivo "y fue excluido el método de las proposiciones simples, concentradas en la afirmación de la verdad o por la condenación neta de los errores". La elección del

52 R. DE MATTei publicó una biografía sobre él, Il crociato del secolo XX. Plinio Corrêa de Oliveira (Piemme, Milano 1996). Cf. del autor: http://www.robertodemattei.it/

53 R. DE MATTEI, Il Concilio Vaticano II, 9.

54 Il Concilio ... 23.

55 Cf. Il Concilio... 6.

56 Cf. www.youtube.com/watch?v=OgyhzlZLz0A

57 R. DE MatTeI, Il Concilio Vaticano II, 591. 
método discursivo tuvo como principal consecuencia la carencia de claridad, causa a su vez de aquella ambigüedad que fue la nota dominante de los textos conciliares" 58 . Esto confirma, desde la sensibilidad opuesta, la observación de J. O’Malley y otros autores sobre la importancia del género literario del Concilio.

El texto de Mattei tiene el mérito de mostrar con nitidez las diversas posiciones de la minoría (Ottaviani, Siri, Carli, Santos, Ruffini, Florit, Browne, Proença Sigaud, Spellman, McIntyre, etc.), sus formas de argumentar, sus profundas decepciones frente al curso que el Concilio tomaba en los más variados temas: la reforma litúrgica, el debate de las dos fuentes, la afirmación de la libertad religiosa, la falta de condena al comunismo, etc. La acusación de modernismo aparece continuamente, no solamente referida a los obispos y teólogos franceses, belgas o alemanes, sino a los mismos papas. Así cierra el capítulo dedicado a la primera sesión, la más importante para la dirección del Concilio en su opinión, "la decisiva" 59 , con una cita del Diario de Luigi C. Borromeo, obispo de Pesaro: "estamos en pleno modernismo" 60 , a juicio de R. de Mattei un vínculo entre estos nuevos progresistas con el modernismo de principio del siglo XX. Su caracterización de la mayoría y de la minoría, la construcción de estos grupos, sus modos de trabajar y acrecentar sus influencias resultan muy interesantes; descripciones completamente opuestas a las que se encuentran en la obra de Alberigo. En opinión de R. de Mattei se trataba originalmente de dos minorías, una romana y tomista y otra antirromana y antitomista, una que representaba la posición oficial del magisterio hasta Pío XII y la otra, heterodoxa, condenada repetidamente por el magisterio ${ }^{61}$. Tengo la impresión que R. de Mattei, al poner de

\footnotetext{
Il Concilio ... 238. Cf. Il Concilio... 242.

Il Concilio ... 293.

Il Concilio ... 283.

61 Aquí el famoso texto de G. PHiLips, de 1963, alabado entonces por Ratzinger y criticado por Tromp, sobre las dos tendencias existentes ("Deux tendances dans la théologie contemporaine," Nouvelle Revue Théologique 85 [1963] 225-38), se confirma como un texto de relieve en aquel momento, similar a una tipología hecha anteriormente por H. DE LUBAC (Carnets du Concile, 2 vols., Paris, Éditions du Cerf, 2007, 34-36; 53-54; 85-87). Me parece interesante la caracterización del episcopado brasilero, en sus respuestas a la consulta de junio de 1959, que realiza L. Baraúna en un artículo de 1993, que Beozzo y Coppe Caldeira comparten: 1) Una minoría ultraconservadora marcada por el tono condenatorio hacia la modernidad y sus valores, especialmente contra el comunismo y la masonería; 2) una minoría
} 
relieve con tanta claridad y de manera repetida la inclinación favorable de Juan XXIII y Pablo VI por los distintos padres conciliares pertenecientes a la mayoría (Suenens, Lercaro, Alfrink, etc.), se aproxima, desde la sensibilidad opuesta, a la posición de Alberigo, a diferencia de la de Marchetto $^{62}$. La discrepancia es que de Mattei lo hace para descalificar a los papas y el curso del Concilio, Alberigo para destacar la línea reformista del mismo. Desgraciadamente, tampoco faltan en el trabajo de R. de Mattei simplificaciones o caricaturas, por ejemplo, cuando afirma que "los progresistas veían el Concilio como una asamblea representativa análoga a las políticas y a los obispos como los mandatarios de la 'voluntad del Pueblo de Dios"'63. Es claroque de Mattei no puede citar ni un testimonio de un padre o teólogo conciliar que justifique esta idea. Una sospecha parece aquí: la idea de Tradición, a la cual se acude repetidamente, se limita a la enseñanza papal de los dos últimos siglos, a lo más a la época postridentina; una perspectiva más amplia que incluya el primer milenio, la experiencia de la iglesia primitiva, incluso el Evangelio, está casi por completo fuera del radar de la investigación.

En este ambiente de investigaciones históricas enrarecido se comprende la reciente solicitud de É. Fouilloux: el futuro de la investigación sobre el Concilio reside en el "retorno a los fundamentos de la disciplina histórica: las fuentes”. Hay mucho por hacer, constata, más allá de la obra de Alberigo y es necesario coordinar los esfuerzos ${ }^{64}$. Por tanto, por una parte, es verdad que la obra de Alberigo significó un giro en los trabajos sobre

que enfatiza la 'Iglesia ad extra', menos en la ad intra, que se posiciona en favor del diálogo, que advierte que llegó el momento de relativizar una pequeña tradición (la postridentina) para rescatar la gran Tradición; 3) una mayoría constituida por conservadores y moderados; apuntan la necesidad de reformas en la liturgia, en la disciplina eclesiástica y el derecho canónico, respetando firmemente la llamada tradición de la Iglesia. Vale la pena preguntarse en qué medida esta caracterización no coincide con la de R. de Mattei. Cf. también la caracterización de J. O’Malley: "El drama del Vaticano II giró precisamente en torno a la tensión entre estos dos polos teológicos, tensión que, por otra parte, no era sino una faceta más de la ya existente entre centro y periferia". ¿Qué pasó en el Vaticano II?, 128. O’Malley refiere, en base a un texto de R. Aubert de 1954, a la "teología romana" que utilizaba métodos preferentemente jurídicos y ahistóricos frente a una teología atenta a la renovación bíblica, patrística, etc., en gran parte, "fenómenos del Norte de Europa”. Cita también el artículo de Philips. Cf. R. De Mattei, Il Concilio Vaticano II, 332, 344, 463, 492, 519, por ejemplo.

63 Il Concilio ... 339.

64 Cf. las expresiones de É. Fouilloux en “Round Table - Vatican II, 1962-2012”, 444. 
el Vaticano II, en buena medida ocasionó el debate hermenéutico y permanece como un punto de referencia obligado. Por otra, como constatan Melloni y Scatena, por ejemplo, y testifica el congreso de Módena, se está ahora en una nueva fase de estudios e investigaciones que sin duda afinará mucho más aún el conocimiento que se tiene del Concilio.

\section{La historia después de la Historia}

Aunque no existe una frontera definida para hablar con precisión de una historia después de la Historia dirigida por Alberigo, la clasificación resulta útil para describir la situación de la investigación. Muchos de los trabajos que refiero a continuación se han iniciado durante o con ocasión de la Historia, pero son líneas de investigación actualmente en ejecución.

a) La importancia de los diarios o memorias conciliares ya fue subrayada por Alberigo al finalizar la Historia del Concilio. En aquel momento se identificaban unos setenta diarios, de naturaleza muy diversa, redactados por personas particulares durante el Vaticano II; algunos ya publicados, muchos todavía inéditos o en curso de publicación. La importancia de esta fuente para el estudio del Concilio ha sido puesta de relieve por varios autores, también sus limitaciones ${ }^{65}$. Ofrecen una mirada personal, individual, sobre los más diversos sucesos (reuniones, participación de

65 Cf. por ejemplo, M. Lamberigts, "The Importance of Diaries for the Study of Vatican II", en K. Schelkens (ed.), The Council Diaries of Edward Schillebeeckx, 1962-1963. Critically annotated Bilingual Edition (Peeters, Leuven 2010), IXXIII. Igualmente, A. Melloni, "I diari della storia dei concilii", en M. D. Chenu, Diario del Vaticano II. Note quotidiane al Concilio 1962-1963 (Il Mulino, Bologna 1996), 9-53. Merecen destacarse los trabajos de difusión de S. Madrigal en lengua española, "Historia 'oficiosa y alternativa' del Vaticano II: a propósito de las Memorias de H. Küng”, Razón y fe 249 (2004) 119-144; Memoria del Concilio. Diez evocaciones del Vaticano II, Madrid, Desclée, 2005 (sobre Congar, Suenens, etc.); Tiempo de Concilio. El Vaticano II en los Diarios de Yves Congar y Henri de Lubac (Sal Terrae, Santander 2009); "El Vaticano II en los 'cuadernos conciliares' de G. Philips”, Razón y fe 259 (2009) 259-284; “El Vaticano II en el 'Diario' de Sebastian Tromp”, Razón y fe 260 (2009) 265-282; Tríptico conciliar. Relato - misterio- espíritu del Vaticano II (Sal Terrae, santander 2012), sobre los diarios de Semmelroth y Schillebeeckx; Unas lecciones sobre el Vaticano II y su legado (San Pablo, Madrid 2012), la primera parte es una reconstrucción histórica basada en las memorias del arzobispo Denis Hurley, de Durban, South Africa; "El Concilio del cardenal Bea”, Razón y fe 266 (2012) 145-158. 
personas, etc.) a menudo corroborada o complementada por otro testigo, que permite adquirir una visión más rica de la red de contactos y trabajos que las actas oficiales revelan. Situados en su justo lugar, representan una fuente imprescindible para el mejor conocimiento del evento. Según varios autores, el de Yves Congar es probablemente el más significativo por su extensión e información ${ }^{66}$, pero existe una cantidad creciente (Betti, Prignon, Philips, Tromp, Döpfner, de Lubac, Willebrands, Ferrari, Suenens, etc.). Por razones geográficas pueden mencionarse, particularmente, las cartas de Hélder Câmara ${ }^{67}$, las crónicas y apuntes de Jorge Mejía ${ }^{68}$ y las Memorias de Silva Henríquez ${ }^{69}$. Acerca de la utilidad concreta de este tipo de fuente, pueden citarse, como ejemplos, el comentario de Hélder Câmara luego de la votación del 20 de noviembre de 1962, cuando por poco más de 100 votos no se alcanzó la mayoría de 2/3 para rechazar el esquema de fontibus revelationis: "La salida [del aula conciliar] fue silenciosa como la del Maracaná, en el campeonato mundial, cuando perdimos con Uruguay"70. O también la referencia de Silva Henríquez a la reacción de los padres conciliares cuando el cardenal Tisserant, el 19 de noviembre de 1964, comunicó a la asamblea que por disposición de Pablo VI se aplazaba la votación de la declaración sobre la libertad religiosa para el año siguiente: "esta gota rebalsó el vaso. En lo que fue la escena más impresionante del Concilio, centenares de padres se pararon al unísono de sus asientos cuando Tisserant terminó de hablar, y comenzaron a retirarse. Varios cardenales partieron hacia la mesa de los moderadores para hacer presente su acalorada protesta por el procedimiento. Los llamados al silencio y al orden se perdieron en la gigantesca conmoción. En el centro del aula se formó espontáneamente una larga fila y los padres comenzaron a firmar una hoja redactada a

${ }_{66}$ Mon journal du Concile (Edition du Cerf, Paris 2002), 2 Vol.: Tomo I. 1960-1963; Tomo II. 1964-1966.

67 H. CÂmara, Lettres conciliaires 1962-1965, I "J'ai déjà un programme bien tracé»; Lettres concilaires 1962-1965, II "Des belles théories à la dure réalité» (Edition du Cerf, Paris 2007). Existe una reedición en portugués en 2009, en el marco de sus obras completas: Dom Hélder Câmara. Circulares Conciliares. Volume I - Tomo I-III, (Cepe Editora, Recife 2009).

68 J. Mejía, Una presencia en el Concilio. Crónicas y apuntes del Concilio Vaticano II (Agape, Buenos Aires 2009).

69 A. Cavallo, Memorias. Cardenal Raúl Silva Henríquez. Tomo I-III (Ediciones Copygraph, Santiago 1991).

70 Dom Hélder Câmara. Circulares Conciliares. Volume I - Tomo I, 118. 
toda prisa por un obispo norteamericano. En media hora se reunieron más de mil firmas. Fue la primera vez que una protesta colectiva, visible y bulliciosa, tuvo lugar en el aula conciliar"71. Es claro que ningún acta conciliar puede suplir este tipo de testimonios. Varios de los trabajos presentados en el congreso de Módena dan cuenta de la vitalidad y de lo mucho que queda por hacer en este ámbito ${ }^{72}$.

b) Existe otra línea de investigación extremadamente importante para un conocimiento más preciso del Vaticano II: aquella que atiende al itinerario redaccional de los diversos documentos conciliares. Naturalmente el procedimiento no es nuevo en relación al Concilio; baste citar los comentarios contenidos en los tres volúmenes del Lexikon für Theologie und Kirche, de la década del 60. Pero ahora han adquirido una nueva calidad fruto de los diversos proyectos de investigación, principalmente los desarrollados en el ámbito del Istituto di Scienze Religiose de Bolonia. Pueden citarse varios ejemplos. Riccardo Burigana, doctor en historia y colaborador del proyecto de dicho Instituto, ha publicado un trabajo sobre la redacción de Dei Verbum que se ubica, precisamente, en el proceso de historización del Concilio mediante el método histórico-crítico promovido por dicho equipo internacional ${ }^{73}$. El texto ha sido recibido con muchos elogios; según A. Dulles, por ejemplo, "es un modelo de trabajo histórico conciliar"74. Otro investigador que formó parte en el proyecto de la Historia de Alberigo es Giovanni Turbanti que, igualmente, fruto de su trabajo doctoral, ha ofrecido un pormenorizado, extenso y muy buen estudio sobre el largo y complejo proceso de confección de la constitución Gaudium et spes ${ }^{75}$. Este texto es un instrumento valioso e imprescindible en el actual estado de investigación conciliar; ha recibido una muy buena acogida. Como reconoce Hans-Joachim Sander en su estudio sobre la constitución pastoral, la obra de Turbanti, junto a la de Ch Moeller publicada inmediatamente después

71 A. Cavallo, Memorias. Cardenal Raúl Silva Henríquez. Tomo II, 39.

72 Otro ejemplo, entre muchos posibles: a partir de los diarios podemos ver cuán dramático fue el debate sobre el esquema acerca de las fuentes de la revelación para varios obispos italianos, cf. G. TURBANTI, "I vescovi italiani alla prova del concilio", Cristianesimo nella storia 34 (2013) 93-129, 106ss.

73 R. Burigana, La Bibbia nel Concilio. La redazione della costituzione 'Dei Verbum' del Vaticano II (Il Mulino, Bologna 1998).

74 A. Dulles, en The Catholic Historical Review 85 (1999) 592-593. "Un trabajo prodigioso", según S. MARrow en Church History 69 (2000) 191-193.

75 G. Turbanti, Un Concilio per il mondo moderno. La redazione della costituzione pastorale 'Gaudium et spes' del Vaticano II (Il Mulino, Bologna 2000). 
del Concilio, representan las principales fuentes históricas para el estudio de este texto conciliar ${ }^{76}$. De manera análoga, otro trabajo digno de relieve es el publicado por Silvia Scatena, académica de la Università di Modena e Reggio Emilia, Italia, y coinvestigadora en el Istituto di Scienze Religiose ya nombrado, dedicado al itinerario redaccional de Dignitatis humanae. Como ella mismo lo reconoce al inicio de su trabajo, se ha beneficiado de una serie de fuentes inéditas conseguidas gracias al proyecto dirigido por Alberigo y por una investigación detallada en archivos de Bélgica y Estados Unidos ${ }^{77}$. Otro trabajo relevante sobre Dei Verbum, aunque dedicado a la historia de la redacción del Esquema De fontibus revelationis, previo al Concilio, cuyo tratamiento y votación negativa en noviembre de 1962 resultó tan importante para el desarrollo del Vaticano II, lo ofrece Karim Schelkens, académico de la KU Leuven. Su texto, fruto de su tesis doctoral, proviene del mismo círculo intelectual, Lovaina (Leuven)-Bolonia ${ }^{78}$, y ha recibido también una crítica muy favorable ${ }^{79}$. El autor cuenta ya con varias buenas publicaciones sobre el Concilio, entre otras, las importantes ediciones del diario de G. Philips y de las notas de E. Schillebeeckx ${ }^{80}$. El ponderado juicio de J. Wicks, al concluir el comentario del libro de

76 Cf. H. J. Sander, "Theologischer Kommentar zur Pastoralkonstitution über die Kirche in der Welt von heute Gaudium et spes", en P. Hünermann; B. J. Hilberath (eds.), Herders Theologischer Kommentar zum Zweiten Vatikanischen Konzil. Band 4 (Herder, Freiburg i.Br. 2005), 581-886, 616. Cf. también los comentarios positivos de G. Routhier, "Recherches et publications récents autour de Vatican II", Laval théologique et philosophique 59 (2003) 583-606, 590-595; J. WICKS, "More Light on Vatican Council II", 94-101.

77 S. Scatena, La fatica della libertà. L'elaborazione della dichiarazione 'Dignitatis humanae’ sulla libertà religiosa del Vaticano II (Il Mulino, Bologna 2003). Es llamativo que el muy buen trabajo de R. SieBENROCK no registre y aproveche este trabajo. Cf. "Theologischer Kommentar zur Erklärung über die religiöse Freiheit, Dignitatis humanae”, en P. Hünermann - B. J. Hilberath, Herders Theologischer Kommentar zum Zweiten Vatikanischen Konzil. Band 4, 125-218. Cf. bibliografía de S. SCATENA en http://personale.unimore.it/rubrica/pubblicazioni/scatena

78 K. Schelkens, Catholic Theology of Revelation on the Eve of Vatican II: A Redaction History of the Schema De fontibus revelationis (1960-1962), (Brill, Leiden 2010).

79 "Una pieza maestra de erudición” según M. Atridge en Theological Studies 73 (2012) 249. Cf. juicios positivos semejantes: J. McCarTin, en Church History 81 (2012) 1033-1034; G. Routhier en Laval théologique et philosophique 67 (2011) 362-366; D. Minch en Ephemerides Theologicae Lovanienses 88 (2012) 537-538.

80 K. Schelkens (ed.), Carnets conciliaires de Mgr. Gérard Philips, secrétaire adjoint de la commission doctrinale (Peeters, Leuven 2006); The Council Diaries of Edward Schillebeeckx, 1962-1963. Critically annotated Bilingual Edition (Peeters, Leuven 
Scatena, puede reflejar bien la importancia de estos emprendimientos: "la nueva ola de investigación del Vaticano II, basada en las Actas recientemente completadas y muchos archivos también organizados recientemente, está proporcionando narraciones e interpretaciones iluminadoras que nos llevan mucho más allá de los estudios tempranos sobre el Vaticano II de 1965-1980. Estas publicaciones recientes sacan a la luz la asombrosa riqueza de pensamiento y orientaciones eclesiales producidos durante el evento epocal que fue el concilio Vaticano II" ${ }^{\prime 1}$. Otro beneficio del emprendimiento de la "escuela de Bolonia"82.

c) Otra línea de investigación que, metodológicamente, está estrechamente emparentada con la anterior es la que estudia un tema determinado y, junto a la pretensión sistemática de comprensión, incorpora un trabajo histórico más o menos detallado sobre la fase preconciliar y el iter redaccional en el mismo Concilio. Pueden citarse, entre otros posibles, tres buenos ejemplos: Pietro Scardilli, profesor en el Studio Teologico S. Paolo de Catania, como fruto de una tesis doctoral en la Universidad Gregoriana, ha publicado en 2007 un trabajo sobre lo que él llama los "núcleos eclesiológicos" de la constitución Sacrosanctum Concilium; incluye un análisis del movimiento litúrgico y el proceso redaccional del documento ${ }^{83}$. Daniele Gianotti, profesor de la Facoltà di Teologica dell'Emilia Romagna, ha publicado en 2010 un texto sobre la patrística en el Vaticano II, particularmente en la Lumen gentium. Como afirma el autor, aunque el texto es el resultado de su tesis doctoral en la Facultad citada, la "sede principal de su investigación” ha sido, una vez más, la Fundación de Bolonia ${ }^{84}$. En esta línea patrística se sitúa otro trabajo de relieve: un detallado artículo sobre Agustín, "el Padre más citado en el Concilio"; de las cerca de 330 citas de Patres y Doctores, fue citado 57 veces, Tomás de Aquino 25. El

2010). Cf. también “Lumen Gentium’s Subsistit in Revisited. The Catholic Church and Christian Unity After Vatican II", Theological studies 69 (2008) 875-893.

81 J. WiCKs, "New Light on Vatican Council II", 628.

82 Dejo fuera de consideración aquí los trabajos históricos incluidos en la obra de P. Hünermann y B.-J. Hilberath, en Herders Theologischer Kommentar zum Zweiten Vatikanischen Konzil, ya que esa perspectiva, la histórica, está incluida y al servicio de un estudio sistemático al que me referiré en una próxima contribución.

83 I nuclei ecclesiologici nella costituzione liturgica del Vaticano II (Editrice Pontificia Università Gregoriana, Roma 2007).

84 I Padri della Chiesa al concilio Vaticano II. La teologia patristica nella Lumen gentium (Edizioni Dehoniane, Bologna 2010), 13. Cf. bibliografía ulterior del autor en http://fter.academia.edu/DanieleGianotti 
autor, Anthony Dupont, investigador de la KU Leuven, estudia no solo las citas explícitas e implícitas de Agustín en los textos conciliares, sino, lo que es más novedoso, en los nueve documentos preparatorios entregados a los Padres conciliares al inicio del Concilio y en noviembre de 1962. "La presencia específica de Agustín en los esquemas conciliares preparatorios no había sido investigado previamente" ${ }^{75}$. El estudio concluye con una comparación entre las citas en ambos tipos de documentos (preparatorios y promulgados) y también con sugerencias precisas para una tarea recién iniciada. Como en tantas otras perspectivas, que ya hemos constatado, "un montón de trabajo está todavía por hacerse" ${ }^{86}$.

d) Paralelamente, el trabajo sobre los más diversos protagonistas del Vaticano II también encuentra un desarrollo creciente. En los materiales presentados en el congreso de Módena, por ejemplo, pueden citarse, entre otros, el de J. Schmiedl sobre la participación de los obispos alemanes en el Concilio; el de G. Turbanti acerca de la compleja situación y los lentos cambios en el aporte de los obispos italianos; el de G. Routhier sobre el rol jugado por varios peritos canadienses en el Concilio, creciente en número e importancia (P. Lafortune, A. Naud, especialmente Jean-Marie Tillard); el de É. Fouilloux sobre la figura del cardenal Eugène Tisserant, decano del colegio cardenalicio y, por este título, segundo personaje de la Iglesia católica en la época del concilio ${ }^{87}$; el de L. Figoureux sobre Henri de Lubac que muestra sus crecientes preocupaciones, particularmente con el llamado Esquema XIII; el de M. Quisinsky sobre Lukas Vischer, pastor reformado suizo observador en el Concilio por el Consejo Mundial de Iglesias; el de M. Mennini sobre el sacerdote francés Paul Gauthier, coordinador del grupo del Colegio Belga interesado en profundizar el tema de la pobreza en la Iglesia, etc.

85 "The Authority of Augustine of Hippo at the Second Vatican Council. A Comparative Analysis of the Use of Augustine in the Preparatory and the Promulgated Documents", en G. Routhier - P. J. Roy - K. Schelkens (ed.), La théologie catholique entre intransigeance et renouveau. Le réception des mouvements préconciliaires à Vatican II (Bibliothèque de la Revue d'histoire ecclésiastique, 95, Collége Érasme, Louvain-la-Neuve - Leuven 2011), 11-48, 13 y 15 respectivamente.

86 La théologie catholique ... 44. Cf. también C. Antonelli, Il dibattito su Maria nel Concilio Vaticano II. Percorso redazionale sulla base di nuovi documenti di archivio (Messaggero di Sant' Antonio, Padova 2009).

87 Además del artículo de Fouilloux, al que se alude, cf. también la biografía que Melloni califica de "investigación ejemplar", Eugène cardinal Tisserant (18841972). Une biographie (Desclée de Brouwer, Paris 2011). 
Otro trabajo reciente digno de considerar que refiere a la temática de los participantes del Concilio es el libro editado por Franz-Xaver Bischof (Ludwig-Maximilians-Universität, Munich). Entre otros temas, el texto incluye seis contribuciones dedicadas a padres y peritos conciliares (Bea, Ottaviani, Döpfner, Suenens, Frings, König, teólogos franceses) ${ }^{88}$. Un ámbito peculiar de estudio lo constituye la participación de laicos en la asamblea conciliar, particularmente la de mujeres como auditoras, por primera vez en la historia de la Iglesia; fueron 23 provenientes de distintos países, presentes recién a partir de la tercera sesión $(1964)^{89}$. También los estudios sobre la participación K. Wojtyla ${ }^{90}$ y, particularmente, la de J. Ratzinger que saca a la luz textos hasta ahora inéditos ${ }^{11}$. En síntesis, el panorama es cada vez más detallado e inabarcable ${ }^{92}$.

88 Das II. Vatikanische Konzil (1962-1965). Stand und Perspektiven kirchenhistorischer Forschung im deutschsprachigen Raum (Kohlhammer, Stuttgart 2012). La publicación es fruto de un congreso celebrado en febrero de 2010 en Munich, con investigadores de lengua alemana (Alemania, Austria y Suiza). Es interesante la constatación de Bischof: no hay en el ámbito alemán un centro de investigación y documentación histórica comparable a los existentes en Italia, Bélgica, Francia, Brasil, Canadá y Estados Unidos; la atención se ha centrado allí más en el campo de la teología sistemática y práctica. El texto de Bischof se completa con un segundo bloque de estudios sobre distintas formas de la recepción del Concilio en dicho ámbito lingüístico.

89 El trabajo más importante al respecto es de C. E. McEnroy, Guests in Their Own House. The Women of Vatican II, (The Crossroad Publishing Company, New York 1996). Cf. la información en J. KомONCHAK, "Hacia una eclesiología de comunión", en G. Alberigo, Historia del Concilio Vaticano II. Volumen IV, 17-97, 33-40.

90 Cf. G. Richi Alberti, Karol Wojtyła: un estilo conciliar. Las intervenciones de Karol Wojtyła en el Concilio Vaticano II (San Dámaso, Madrid 2010). Publica, además de un estudio preliminar y unas introducciones, todas las intervenciones orales y escritas en edición bilingüe, incluyendo la respuesta a la consulta de 1959. Tiene ya una traducción italiana en 2012 .

91 Cf. J. Wicks, "Six Texts by Prof. Joseph Ratzinger as peritus before and during Vatican Council II”, Gregorianum89 (2008) 233-311; J. RatZINGER, Gesammelte Schriften. Zur Lehre des Zweiten Vatikanischen Konzils. Formulierung - Vermittlung - Deutung. Band 7/1; Gesammelte Schriften. Zur Lehre des Zweiten Vatikanischen Konzils. Formulierung - Vermittlung - Deutung. Band 7/2 (Herder, Freiburg 2012).

92 Cf. J. Schmiedu, "Die deutschen Bischöfe während des Konzils. Wie das Zweite Vatikanum die deutsche katholische Kirche veränderte", Cristianesimo nella storia 34 (2013) 69-91; G. Routhier, "Le rôle joué par les periti Canadiens à Vatican II", Cristianesimo nella storia 34 (2013) 201-235; É Foullloux, "Le cardinal Eugène Tisserant à Vatican II", Cristianesimo nella storia 34 (2013) 237-247; L. Figoureux, "Henri de Lubac et le concile Vatican II, espoirs et inquiétudes d'un thélogien", Cristianesimo nella storia 34 (2013) 249-271; M. Quisinsky, "The 
Particular importancia, aunque no demasiados estudios, tuvo la organización de padres conciliares pertenecientes a la minoría en torno al llamado Coetus Internationalis Patrum; un grupo que poseyó una treintena de simpatizantes y, según la ocasión, unos 250 firmantes o adherentes. Afortunadamente, la situación historiográfica está recibiendo un enriquecimiento importante en estos años. Philippe Roy, de la Université Laval, ha presentado en noviembre de 2011 una tesis doctoral, todavía inédita, a partir de la cual se están editando buenos artículos, que significan un verdadero paso adelante en la investigación ${ }^{93}$. En 2012 ha publicado un interesante artículo panorámico que describe brevemente la situación historiográfica del asunto, el origen progresivo de este grupo a medida que el Concilio tomaba una orientación insatisfactoria para este grupo de personas, hasta su reconocimiento explícito con el nombre con el cual se lo conoce ya en la tercera sesión conciliar; también se pone de relieve su modo de trabajo y de influir en la confección de los diversos documentos. Tiene razón la constatación de Roy en su conclusión: aunque el grupo no consiguió torcer la orientación general del Concilio, ni tampoco cambiar importantes decisiones referidas a la eclesiología (colegialidad), liturgia (lengua vernáculas), afirmación de la libertad religiosa, promoción del ecumenismo, ni añadir una explícita condena al comunismo o nuevas definiciones marianas, su oposición condujo a la suavización de ciertas afirmaciones o a la atenuación de ciertas enseñanzas; los textos no tendrían en más de un aspecto el carácter de textos de compromisos sin el influyente trabajo que desarrollaron ${ }^{94}$. En otra contribución, en el marco del Congreso de Québec citado, Philippe Roy ha presentado otro interesante artículo sobre este grupo conciliar, particularmente referido a su "prehistoria" como la llama. La tesis central,

ecumenical dynamic of Vatican II - Lukas Vischer between Geneva and Rome", Cristianesimo nella storia 34 (2013) 273-314; M. Mennini, "Paul Gauthier e la povertà della Chiesa durante il Vaticano II. La faticosa ricerca di un consenso", Cristianesimo nella storia 34 (2013) 391-422.

93 El título: Le Coetus Internationalis Patrum, un groupe d'opposants au sein du concile Vatican II, dirigida por G. Routhier y J.-D. Durand, Université Laval -Université Jean Moulin Lyon 3. Está en curso de publicación en Édition du Cerf. El resumen es ilustrativo, cf. www.theses.fr/2011LYO30077. Cf. también www.philipperoy. org/Page_daccueil.html

94 Cf. P. J. Roy, "Le Coetus Internationalis Patrum au concile Vatican II: genèse d'une dissidence?”, Histoire@Politique.Politique,culture, société 18 (septembre-décembre 2012) [on line, www.histoirepolitique.fr]. 
quizás, reside en que, a su juicio, los obispos Lefebvre, Sigaud, Mayer y otros defendieron en el Concilio nada menos que un habitus teológico que habían recibido en su formación romana, antiliberal y contrarrevolucionaria. Los principales miembros del Coetus Internationalis Patrum tuvieron un punto común: los estudios en Roma. Se trata de tres instituciones: ante todo, el Seminario Francés de Roma, también en diversa medida y forma la Universidad Gregoriana (donde fueron alumnos los tres citados, además de G. Siri, etc.) y la Universidad Lateranense (Ottaviani, Larraona, Ruffini, Browne, Carli, etc.). Para formular esta tesis, los testimonios de los mismos autores son importantes. Afirmada esa base educativa común, el autor reconoce que "un estudio más preciso podría mostrar matices en la romanidad dispensada por los educadores de estos establecimientos, en particular por la Gregoriana y el Laterano"95.

Por razones geográficas, proximidad a nosotros, puede citarse, sobre todo, el excelente trabajo de José Oscar Beozzo ${ }^{96}$. Estudia la participación de los obispos brasileros a lo largo de todo el itinerario conciliar, desde las primeras reacciones ante el anuncio de Juan XXIII en 1959 hasta las sesiones finales en 1965, incluida la formulación del famoso Plan de Pastoral de Conjunto de los obispos brasileros, redactado durante el Concilio ${ }^{97}$. Beozzo destaca que en el Vaticano I solo hubo 7 obispos

95 "La préhistorire du Coetus Internationalis Patrum. Una formation romaine, antilibérale et contra-révolutionnaire", en G. RouthiER - P. J. Roy - K. SCHELKENS, La théologie catholique entre intransigeance et renouveau, 321-354, 352. Salvo Carli, los citados en el segundo grupo no eran miembros, pero sí adherentes del Coetus. Cf. también P. Roy, "Le Coetus Internationalis Patrum et les juifs au concile Vatican II. Du chapitre IV de schéma De Ecumenismo à la déclaration Nostra Aetate", Ephemerides Theologicae Lovanienses 88, 4 (2012) 299-328.

96 Cf. J. O. Beozzo, A Igreja do Brasil no Concílio Vaticano II 1959-1965 (Paulinas, São Paulo 2005). Es el fruto de una tesis doctoral presentada en 2001, en San Pablo, Brasil.

97 La lectura de las respuestas de los obispos brasileros, los vota, a la consulta implementada por Juan XXIII en junio de 1959 (pp. 77-121) confirma que esta información es muy valiosa para evaluar el significado del Concilio, particularmente, la distancia que existe entre las expectativas y sugerencias de entonces con lo debatido y decidido en el Concilio mismo. A este respecto, conserva todo su valor la obra dirigida por J. O. Beozzoque presenta un análisis de los vota de los obispos argentinos, chilenos, paraguayos, peruanos, colombianos, venezolanos, centroamericanos, mexicanos y del Caribe. Cf. Cristianismo e Iglesias de América Latina en vísperas del Vaticano II (DEI, San José de Costa Rica 1992). El texto es el resultado de un simposio realizado en Houston, Texas, en enero de 1991, en el marco del proyecto de la Historia de Alberigo. 
brasileros participantes (eran 11 en total), de los 744 padres conciliares; en la apertura del Vaticano II, 204; en 1962 el episcopado brasilero era, en número, el tercero del mundo, luego del italiano y del norteamericano. La hipótesis del libro es que a lo largo de la preparación y, particularmente, de la celebración del Concilio, con sus largas semanas de estancia en Roma, se ofreció la oportunidad para esbozar la identidad propia de un episcopado muy diverso por sus orígenes y pertenencias (brasileros y extranjeros, religiosos y seculares), por sus situaciones geográficas; una nueva identidad enraizada en la convivencia (compartieron una casa en Roma, la Domus Mariae), también mediante una visión común adquirida en los debates conciliares, desembocando en un plan de trabajo conjunto. Beozzo estudia el particular impacto del Concilio sobre la Iglesia del Brasil y también la contribución brasilera al desarrollo del Concilio, con especial atención al cuerpo episcopal, también a los peritos y a la tarea de un puñado de laicos/as. La tercera parte de la obra incluye una detallada "Prosopografia do episcopado brasileiro"; un trabajo de una minuciosidad poco común ${ }^{98}$. Según mi conocimiento no existe otro estudio semejante al de Beozzo sobre otras iglesias de América Latina.

Otro trabajo brasilero de muy buen nivel es el material ofrecido por Rodrigo Coppe Caldeira, profesor en la Pontificia Universidade Católica de Minais Gerais, Belo Horizonte. Es interesante la constatación del autor al inicio de su contribución en el congreso de Québec, de octubre de 2010, ya citado: "Los estudios sobre el Vaticano II (1962-1965) y su recepción en Brasil son pobres. Más allá de su casi inexistencia a nivel académico, los que existen adoptan un tipo de interpretación conforme,

98 Un ejemplo: una de las principales actividades en la casa Domus Mariae fueron las conferencias a lo largo de todo el Concilio, 94 en total; de manera informal y ocasional en la primera sesión (10 conferencias) y de modo sistemático en las siguientes. A partir de diversas fuentes, Beozzo reconstruye día, hora, invitado, tema y lengua de cada conferencia. Participaron los más variados interlocutores (Küng, Bea, Ratzinger, Thurian, Schutz, Häring, de la Potterie, Schillebeeckx, Philips, Arrupe, Congar, Cullman, Lyonnet, de Lubac, Daniélou, Gitton, etc.). El que más veces asistió fue Karl Rahner, quien hablaba en latín; él último, el cardenal Leo Suenens, el 6 de diciembre de 1965, que habló en francés sobre "El balance del Concilio". Cf. A Igreja do Brasil, 195-219. En este contexto se comprende el testimonio de Agnelo Rossi, entonces arzobispo de Ribeirão Preto, Brasil, que BEOzzo recuerda: "Fuimos alumnos de la mejor, de la más selecta, de la más importante universidad del mundo. Volvimos a los bancos escolares teniendo como compañeros a hombres de todas las razas y de todos los pueblos”, ibid., 195. 
ideológicamente situada en el campo teórico de lo que en el país se conoció como la teología de la liberación... gracias también a la influencia de este modo de considerar la teología y el lugar de la Iglesia en el mundo, los historiadores y sociólogos se concentraron sobre el estudio del catolicismo en el país simplemente a través de personajes de la llamada 'izquierda católica', o del 'catolicismo progresista', olvidando los importantes actores sociales, es decir, el 'conservadorismo católico"'99. De allí la intención de su tesis doctoral, ${ }^{100}$ afirma el autor, "deseaba mostrar como D. Geraldo de Proença Sigaud, obispo de Diamantina - uno de los principales nombres del catolicismo conservador y antimoderno brasilero- fue, junto con Marcel Lefebvre y Antônio de Castro Mayer, uno de los principales actores en la organización de la 'minoría conciliar"'101. Efectivamente, como recuerda J. B. Libanio, esa misma Iglesia, la brasilera, que llegó a ser una "Iglesia de vanguardia en el mundo" luego del Concilio, "tenía en su seno uno de los grupos conservadores más aguerridos que actuó organizadamente en el concilio Vaticano II" ${ }^{102}$. Todos los estudios históricos citados ponen de relieve el liderazgo de estos dos obispos brasileros en el desarrollo del Vaticano II.

Pablo Dabezies, historiador uruguayo y miembro del clero de Montevideo, ha publicado trabajos referidos a la participación del episcopado uruguayo en el Concilio. Su tesis doctoral, de 2009, refiere a las relaciones Iglesia-sociedad en los documentos episcopales del Uruguay entre 1965 y 1985 . En este sentido es acertada su observación sobre su libro: "Creo que puedo definir mi esfuerzo como una contribución al estudio

99 R. Coppe Caldeira, "Le conservatisme catholique au Brésil. Aspects historiques avant le Concile Vatican II", en G. Routhier - P. J. Roy- K. Schelkens, La théologie catholique entre intransigeance et renouveau, 309-320, 309.

100 Cf. Os baluartes da tradição: o conservadorismo católico brasileiro no Concílio Vaticano II (Editora CRV, Curitiba 2011).

101 R. Coppe Caldeira, "Le conservatisme catholique au Brésil”, 310. Cf. también "Bispos conservadores brasileiros no Concílio Vaticano II (1962-1965): D. Geraldo de Proença Sigaud e D. Antônio de Castro Mayer”, Horizontes 9, 24 (2011) 10101029. Cf. la precisa información sobre ambos ofrecida por J. O. BeOzzo , A Igreja do Brasil no Concílio Vaticano II, 401, 441. Cf. también R. Coppe Caldeira, "Um bispo no Concilio Vaticano II: D. Geraldo de Proença Sigaud e o 'Coetus Internationalis Patrum”, Revista eclesiástica brasileira 282 (2011) 390-418.

102 J. B. Libanio en su descriptiva y elogiosa recensión a la tesis de R. Coppe Caldeira, en Horizonte 24 (2011) 1197-1201. 
de la recepción del Vaticano II en la comunidad eclesial uruguaya" ${ }^{103}$. No obstante, el autor dedica unas páginas a describir el momento conciliar (pp. 111-119), en referencia a otro texto suyo publicado años antes: un artículo fruto de un coloquio internacional, en Bolonia en 1996, en el marco del proyecto internacional de Alberigo ya citado. Aunque mucho más breve, se aproxima, por el estilo, a la obra de Beozzo. Incluye no solo el trabajo de los 12 obispos uruguayos durante el Vaticano II, sino que también dedica unas páginas a presentar las respuestas a la consulta del cardenal Tardini en 1959. Los múltiples límites, pero también sus aportes, frecuentemente vinculados a otros episcopados (el chileno, en primer lugar) e intereses, aparecen bien delineados ${ }^{104}$.

Loris Zanatta, profesor de la Universidad de Bolonia, publicó, también en el marco de la investigación de Alberigo, un extenso artículo referido a la participación de los obispos argentinos en la primera sesión conciliar. Gracias a su conocimiento de la historia de la Iglesia argenti$\mathrm{na}^{105}$, el autor logra contextualizar en el escenario argentino político y eclesiástico el trabajo más específico sobre la primera sesión del Vaticano $\mathrm{II}^{106}$. Sus fuentes principales, puede decirse, son, además de las actas oficiales, los diarios personales de los obispos Alberto Devoto y Vicente Zazpe y la revista Criterio con Jorge Mejía, su director. A partir de estas fuentes, particularmente, consigue reconstruir lo que se conoció con el nombre de Coetus argentino, el cual incluía un grupo de obispos poco numeroso (Aguirre, Devoto, Kemerer, Marengo, Ponce de León, Zazpe), ayudado por varios peritos (Catena, Giaquinta, Mejía, Nolasco y Trusso; a veces también Pironio) que, aunque marginal en el episcopado argentino, progresivamente fue sintiéndose más autorizado con el desarrollo de la primera sesión conciliar. Zanatta revisa los diferentes aportes de la sesión de 1962 con ocasión del debate de los distintos esquemas. Resaltan allí las profundas diferencias en el episcopado argentino, par-

103 No se amolden al tiempo presente. Las relaciones Iglesia-sociedad en los documentos de la Conferencia Episcopal del Uruguay (1965-1985), (OBSUR, Montevideo 2009), 50.

104 “Los Obispos del Uruguay en el Concilio Vaticano II", Soleriana 11 (1999) 11-48.

105 Cf. R. Di Stefano - L. Zanatta, Historia de la Iglesia argentina. Desde la Conquista hasta fines del siglo XX, Grijalbo Mondadori, Buenos Aires 2000).

106 Cf. L. ZanatTa, "Il 'mal di Concilio' della Chiesa argentina. Radiografia di un Episcopato al Vaticano II. Prima sessione e intersessione. Ottobre 1962 - Settembre 1963”, en M. T. Fattori - A. Melloni (eds.), Experience, Organizations and Bodies at Vatican II (Bibliotheek van de Faculteit Godgeleerdheid, Leuven 1999), 141-216. 
ticularmente el liderazgo conservador de Antonio Caggiano, cardenalarzobispo de Buenos Aires. El marcado contraste en las intervenciones en el aula conciliar el mismo día 16 de noviembre, en medio del debate sobre el esquema de fontibus revelationis, entre Caggiano y Silva Henríquez, cardenal-arzobispo de Santiago de Chile, refleja la mentalidad de dos iglesias distintas. Un estudio detallado de la participación de los obispos argentinos está pendiente; su relativa importancia entonces, siquiera numérica, no puede desconocerse. Como muestra Zanatta, con 66 padres conciliares formaban el décimo episcopado en la asamblea y el primero de la América de lengua castellana. Además, afirma el historiador italiano, "la Santa Sede desde hacía mucho tiempo había asignado a la iglesia argentina un implícito rol de leadership de la cristiandad entre los países de la América hispana" ${ }^{107}$. Probablemente esto explica la presencia del cardenal Caggiano, como único purpurado latinoamericano, en el consejo de presidencia del Concilio desde 1962.

Particular interés tiene también el trabajo, siquiera incipiente, sobre algunas figuras del Cono sur, ante todo, la del activo cardenal Rául Silva Henríquez, que en el aula conciliar tomó la palabra en varias oportunidades, en nombre propio y de decenas de padres latinoamericanos, en referencia a los principales asuntos del debate conciliar (la reforma litúrgica, el esquema de fontibus revelationis, la organización del esquema de la futura Lumen gentium, la ubicación de la mariología al interior de la eclesiología, la libertad religiosa, el ecumenismo, etc.). Puede decirse que, compitiendo con la atención prestada a H. Câmara (quien nunca tomó la palabra en el aula conciliar), el cardenal chileno aparece como el padre conciliar latinoamericano más activo, o por lo menos más citado, en las principales obras de historia existentes ${ }^{108}$. Al respecto, es interesante la observación de J. O. Beozzo:

107 Ibid., 144

108 Fue presidente de la Comisión para el apostolado de los laicos. Cf. R. Álvarez Gutiérrez, "La participación teológica del cardenal Raúl Silva Henríquez en el Concilio Vaticano II: una clave para entender el espíritu y la letra del mismo", Revista católica 110, 1167 (2010) 223-243; R. DE MATteI, Il Concilio Vaticano II, 219, 251, 259, 311, 322, 347, 392, 396, 441, 461, 524. Lo ubica, como uno de los líderes, entre los latinoamericanos que poseían "posiciones extremas", junto a H. Câmara y M. Larraín. Cf. algunos ejemplos de su rol destacado en la obra de G. Alberigo, Historia del Concilio Vaticano II. Volumen II, 120 (a favor del esquema litúrgico, noviembre de 1962), 122-123 (apoya la descentralización, la responsabilidad de las conferencias episcopales en el uso de las lenguas vernáculas), 
"En América Latina, Chile fue el país que, al lado de Brasil, tuvo la participación más intensa y organizada en el Concilio, gracias a la actuación del Cardenal Raúl Silva Henríquez, respaldado por los estudios de teólogos de la Facultad de Teología de la Universidad Católica de Santiago y el obispo de Talca, Manuel Larraín Errázuriz, vice-presidente del Celam y luego presidente de la entidad durante el período conciliar"109.

Es exactamente la opinión del mismo cardenal en sus Memorias: años después escribe que, para el inicio del Concilio, “yo ya sabía que éramos uno de los equipos más preparados de América Latina, tal vez uno de los pocos que había estudiado con tanta dedicación los temas que se

150 (sobre liturgia), 243 (sobre la pastoralidad en el esquema de fontibus), 245 (contra el mismo esquema), 368 (sobre el esquema de ecclesia chileno); Historia del Concilio Vaticano II. Volumen III, 55 y 60 (diversos aportes sobre el de ecclesia, octubre de 1963; el 1 de octubre en nombre de 440 latinoamericanos, según J. O’Malley, ¿Qué pasó en el Vaticano III, 240), 66 (en nombre de 77 padres latinoamericanos, el 8 de octubre 1963), 85 (ulteriores aportes al debate sobre Iglesia, octubre de1963), 131 (una iniciativa suya, una carta al Papa en noviembre de 1963, firmada por 500 obispos y que luego C. Soetens, en pág. 265, a partir de una información de J. Grootaers, califica como "el paso más conocido para animar al Papa a reformar la Curia y a asociar al episcopado en el gobierno de la Iglesia"), 398 (sobre el "proyecto chileno" de eclesiología); G. AlberIGo, Historia del Concilio Vaticano II. Volumen IV, 37 (solicita que laicos tomen la palabra en el aula conciliar, 7 de octubre de 1964), 84 (testimonio de un diálogo muy importante con Pablo VI en el marco de las importantes votaciones de setiembre de 1964 sobre la colegialidad episcopal), 110, 120, 125 y 180 (intervenciones a favor de la libertad religiosa), 265, 267, 270, 278 y 280 (octubre de 1964, sobre la futura GS); G. Alberigo, Historia del Concilio Vaticano II. Volumen V, 79 (nuevamente sobre la libertad religiosa, a favor del esquema, septiembre de 1965), 134 y 135 (sobre GS, apoyo al esquema, setiembre de 1965), 139 (crítica suya a la ambigüedad del título "constitución pastoral", pedía quitar el "pastoral"), 160 y 161 (sobre la discutió en torno al matrimonio de GS), 187 y 188 (importante intervención sobre el reglamento en torno al esquema sobre la formación sacerdotal, octubre de 1965), 200 (cofirmante de una carta que expresa insatisfacciones por el documento sobre educación, octubre de 1965). Cf. también P. DabeZIEs,"Los Obispos del Uruguay en el Concilio Vaticano II", 33s., 36ss.

109 J. O. Beozzo, A Igreja do Brasil, 36. Cf. también A Igreja 180-181. Es interesante constatar la situación diferente de Chile y Brasil que, aunque Beozzo no lo tematiza expresamente, se deduce de su obra. El autor dedica un capítulo a la temática de los peritos, los expertos, muestra la ausencia de asesores del episcopado brasilero al inicio del Concilio, porque había teólogos "escasamente preparados para la tarea conciliar" (p. 297), y la necesidad de apelar a teólogos europeos. Finalmente, el episcopado brasilero contó con 9 peritos, 7 de ellos recién en las dos últimas sesiones. 
tratarían"110. Y como evaluación, al final de la asamblea: "a pesar de nuestro modesto tamaño numérico, que era superado por buena parte de los episcopados de América Latina, nos situamos en la vanguardia del Concilio y establecimos un diálogo de iguales con algunas de las más relevantes figuras europeas"111.

e) Un campo muy interesante en las actuales investigaciones históricas lo representa el estudio de la recepción de los diversos movimientos preconciliares en el Vaticano II. Se trata de un punto de referencia importante para la comprensión del mismo Concilio puesto que este, en buena medida, fue el fruto de los años que lo precedieron. El siglo XX ha sido caracterizado como la "época de los movimientos": litúrgico, bíblico, patrístico, catequístico, mariano, ecuménico, misionero, también la llamada Nouvelle Théologie y la Acción Católica, etc. Por un lado, es claro que la larga preparación del Concilio no se redujo a los tres años anteriores, 1959-1962. Por otro, es verdad que parte de la historiografía actual considera con cierta simpleza que los esquemas preparatorios no fueron más que la expresión de corrientes teológicas intransigentes, conservadoras, de la primera mitad del siglo XX, mientras que el Concilio, a partir de la reformulación en la primera sesión e intercesión, significó la asunción de las ideas desarrolladas de manera subterránea en los otros movimientos. Se trata de una construcción esquemática, bipolar necesitada de un mayor discernimiento, como si el período preparatorio no hubiera contribuido a la evolución de las ideas y a una primera re-

110 A. Cavallo, Memorias. Cardenal Raúl Silva Henríquez. Tomo I, 261. Algo semejante afirma al comentar el final de la segunda sesión: "La actuación del Episcopado chileno en esta segunda sesión consolidó la imagen, ya adquirida en la primera, de que se trataba de uno de los cuerpos mejor organizados de América Latina [...]. El balance fue notable incluso en términos numéricos: presentamos 132 enmiendas al esquema sobre la Iglesia, 31 al del Ecumenismo y otras diez en puntos diversos de otros textos; sacamos un proyecto completo de refundición del esquema sobre los Obispos y entregamos otro sobre el capítulo de la Virgen María. Estuvimos presentes en todos los temas y los debates más relevantes de la segunda sesión. Y nos convertimos, inesperadamente, en el grupo más consultado por otras conferencias episcopales de América Latina”, Memorias Cardenal Raúl Silva Henríquez. Tomo I, 318-319. Cf. también A. Cavallo, Memorias. Cardenal Raúl Silva Henríquez. Tomo II, 71.

111 Memorias. Cardenal Raúl Silva Henríquez. Tomo II, 7. 1. Sobre la figura del argentino E. Angelelli, cf. el trabajo, fruto de su tesis doctoral, de L. Liberti, Mons. Enrique Angelelli. Pastor que evangeliza promoviendo integralmente al hombre (Guadalupe, Buenos Aires 2005), particularmente, su participación en el Concilio en páginas 96-132. 
cepción de esas “ideas nuevas” elaboradas también en la primera mitad del siglo XX. Las investigaciones en curso procuran precisar la presencia concurrente de estas dos tendencias, poniendo en relación los años preconciliares y la fase preparatoria de manera de situar mejor el Concilio en una duración larga y estudiarlo como un hecho de recepción de desarrollos de largo alcance en el cuerpo eclesial. En este sentido, piensan los autores de la publicación, el congreso realizado en la Université Laval, Québec, en octubre de 2010,y la obra que se edita no hace más que abrir la investigación; se trata de "un primer trabajo" que muestra la complejidad del ambiente católico, en absoluto homogéneo ${ }^{112}$.

f) Otros campos de trabajo, algunos recién a los inicios, ofrecen perspectivas complementarias interesantes. Piero Doria, del Archivio Segreto Vaticano, muestra la historia, la situación actual y nuevas propuestas de investigación a partir de la documentación todavía inédita; la documentación publicada, fundamentalmente las Actas, no obstante su importancia, resultan insuficientes ${ }^{113}$. En este sentido, ha recibido una muy buena valoración un trabajo de Mauro Velati dedicado a un aspecto inexplorado todavía: la documentación de las comisiones, en este caso del Secretariado para la unidad de los cristianos ${ }^{114}$. Interesante es también un aporte de José Oscar Beozzo; muestra un nuevo campo de investigación con la "desaparición" de textos de las Actas conciliares sobre el tema de la ordenación sacerdotal de hombres casados ${ }^{115}$. Federico Ruozzi, de la Fondazione per le scienze religiose de Bolonia, concreta un trabajo sobre una tipología de fuente conciliar todavía poco estudiada: las grabaciones realizadas entonces por Radio Vaticana, unas 762 horas ahora digitalizadas, de las discusiones de las congregaciones generales

112 Cf. G. Routhier - P. J. Roy- K. Schelkens, La théologie catholique entre intransigeance et renouveau, 13.

113 P. DoriA, "L'Archivio del Concilio Vaticano II: inventario e nueve proposte di ricerca", Cristianesimo nella storia 34 (2013) 29-40, 38. Cf. también, P. DORIA, "L’Archivio del Concilio Vaticano II: storia e sviluppo", Anuario de historia de la Iglesia 21 (2012) 135-155.

114 Cf. M. Velati, Dialogo e rinnovamento. Verbali e testi del segretariato per l'unità dei cristiani nella preparazione del concilio Vaticano II (1960-1962), (Il Mulino, Bologna 2011).

115 Cf. "Intervenções episcopais desaparesidas dos Acta Synodalia do Vaticano II: a ordenação presbiteral do homens casados e o celibato eclesiastico", Cristianesimo nella storia 34 (2013) 41-56. BEOzZO ya había afrontado el asunto en su trabajo de 2005, cf. A Igreja do Brasil, 265-271. 
y de la Comisión teológica ${ }^{116}$. Una constatación parecida hace Angelo Lameri, de la Università Lateranense, sobre el estudio de la fase preparatoria del documento sobre la liturgia, "está todavía en los inicios"117. Franz-Xaver Bischof, por su parte, constata el "cambio dramático", positivo, acaecido con la apertura de los archivos diocesanos alemanes a partir del año 2000, lo cual ofrece una nueva fuente de investigación ${ }^{118}$. También Mathijs Lamberigts sugiere otros ámbitos de trabajo históricos, grupos de personas a los que llama "los participantes silenciosos": el aporte de los superiores generales de diversas órdenes religiosas, de peritos de conferencias episcopales como la de Indonesia, del material de J. Cardijn, incluso, piensa, existe una apreciable cantidad de fotos capaces de mostrar, por ejemplo, la realización de meetings informales, de manera análoga a como lo hace Congar en su Diario ${ }^{119}$. Otro campo de investigación bastante inexplorado anota C. Theobald: emprender un verdadero trabajo histórico sobre los 50 años de recepción, de instrumentalización o no recepción del Vaticano II; en su opinión, el trabajo de G. Routhier en Canadá es ejemplar ${ }^{120}$. Lo advertía Alberigo al final de su Historia: "Pudiera ocurrir, y este orador lo espera ardientemente, que la historia del Concilio vaya seguida por una historia de su recepción, una tarea no menos exigente y dificultosa" ${ }^{121}$.

\section{REFLEXIONES FINALES}

Del camino recorrido se pueden extraer múltiples constataciones que, por una parte, muestran el estado de situación de los estudios históricos sobre el Vaticano II y, por otra, indican las perspectivas de investigación de los próximos años. No deseo repetir aquí las evaluaciones hechas a lo largo de la contribución, sino solo destacar algunos resultados.

116 Cf. F. RuOzzI, Il concilio in diretta. Il Vaticano II e la televisione tra informazione e partecipazione (Il Mulino, Bologna 2012); "La voce del concilio. El fuorionda del 13 ottobre 1962 nelle fonti audio del Vaticano II", Cristianesimo nella storia 34 (2013) 161-199.

117 A. LAmeri, "L'esordio dei lavori della «Pontificia Commissio de Sacra Liturgia praeparatoria Concilii Vaticani II»", Cristianesimo nella storia 34 (2013) 131-159, 131.

118 Cf. F.-X. Bischof, "On the State of German-speaking research on Vatican II", 58.

119 Cf. las expresiones de M. LAmberigTs en "Round Table - Vatican II, 1962-2012", 437-441.

120 Cf. las expresiones de C. Theobald en "Round Table - Vatican II, 1962-2012", 449-452.

121 Historia del Concilio Vaticano II. Volumen V, 11. 
El trabajo de la Historia de Alberigo en cinco volúmenes representa una obra mayor que divide aguas. La recolección de fuentes, el fondo bibliográfico, el trabajo en equipo internacional y la metodología de investigación de la Fondazione per le scienze religiose de Bolonia no tiene comparación y ha colaborado, no solo a la publicación de la Historia, sino a la realización de muchas de las mejores investigaciones existentes. Junto a Bolonia, no hay duda que entre los principales centros de investigación histórica se sitúan Lovaina (KU Leuven) y, en menor medida, Québec.

El asunto hermenéutico ocupa un rol primario en las lecturas históricas. Los aportes de Alberigo y de O'Malley, a los cuales he aludido siquiera brevemente, son explícitos y muy destacables. La pretensión de escribir una "verdadera historia" o de realizar una presentación "objetiva”, como formulan Ruini y Marchetto, navega entre la ingenuidad y la politización del debate. La obra de R. de Mattei muestra que escribir y leer textos con perspectivas diferentes pueden enriquecer el debate y sacar a la luz aspectos que en otra posición quedan opacados. Un punto de vista particular no es solo una limitación, ineludible por lo demás, es también una oportunidad. Este libro confirma que los lentes con que se miran los procesos históricos resultan determinantes. Incluso porque una obra no puede materialmente dar cuenta de todo y por ello debe elegir y seleccionar. Lo que se espera de un historiador de nuestro tiempo, en la llamada "edad hermenéutica de la razón” y "después de Freud", es que sea consciente (intente serlo) de su punto de vista particular, lo someta continuamente a crítica, cultive una particular sensibilidad por la alteridad y por el respeto a la siempre compleja realidad, ejercite una continua sospecha sobre las determinaciones inconscientes de su discurso. En cualquier caso, de las publicaciones de la última década emerge, así creo, una enseñanza precisa: la importancia del estudio histórico y el análisis hermenéutico-teológico estrechamente vinculado. De hecho, los trabajos más significativos en esta segunda perspectiva (Routhier, Hünermann, Theobald, Ruggieri, etc.), que no he considerado en esta contribución, están acompañados por un gran conocimiento del evento mismo.

A la luz del trabajo ejemplar de J. O. Beozzo puede advertirse mejor un extenso programa de trabajo que habría que concretar en América Latina. El repetido argumento, acertado en muy buena medida, de un concilio hecho por europeos para afrontar problemas generados en la historia europea debe complementarse con un estudio de los diferentes 
líderes y perspectivas latinoamericanos. Los ejemplos aludidos acerca de los padres conciliares, el brasileño Hélder Câmara y el chileno Silva Henríquez son dos puntas de iceberg de posibles trabajos futuros. No parece una casualidad el hecho de que Beozzo haya participado en el proyecto de Alberigo; benefició a ambos.

Los congresos citados de Módena y Québec, por ejemplo, muestran que existe mucha gente joven abriendo nuevos caminos. La participación latinoamericana es escasa. ¿Sería posible formular una estrategia para investigaciones ulteriores desde diversas instancias de nuestro continente, facultades, centros de investigación, sociedades de estudios históricos y teológicos? 
Resumen: La bibliografía científica sobre el Vaticano II es muy numerosa y de una calidad muy variada. Es necesario un discernimiento. Para analizarla es posible distinguir tres áreas. En primer lugar, una histórica, que atiende al evento mismo, su preparación y desarrollo. Segunda, los estudios sistemáticos, en los cuales se destaca particularmente la perspectiva hermenéutica. Tercera, panoramas o investigaciones puntuales que refieren a los diversos y múltiples procesos de recepción, principalmente por el criterio regional. No es posible trazar una línea clara de división en muchos autores y trabajos que pertenecen a más de una de las áreas referidas. El presente artículo da cuenta solamente de las investigaciones históricas y desarrolla este propósito: presentar los textos y autores/as más relevantes, discernir las líneas de trabajo y argumentos principales que están ocupando a la comunidad teológica internacional; destaca de modo particular los aportes latinoamericanos.

Palabras clave: Concilio, Alberigo, Marchetto, O'Malley, de Mattei

Abstract: The scientific literature on Vatican II is very large and of varied quality. Discernment is needed. In its analysis, three areas can be distinguished. First, a historical one, which studies the event itself, its preparation and development. Second, the systematic studies, in which particular emphasis is placed on the hermeneutic perspective. Third, panoramas or specific research that relate to the various and multiple processes of reception, mainly by the regional approach. This article gives an account only of the historical research. The purpose is to present the most relevants texts and authors and discern the lines of work and main arguments. The text highlights in a particular way the latin american contributions.

Keywords: Council, Alberigo, Marchetto, O'Malley, de Mattei 
